Article

\title{
Optimal Pricing and Green Product Design Strategies in a Sustainable Supply Chain Considering Government Subsidy and Different Channel Power Structures
}

\author{
Kelei Xue ${ }^{1}$, Guohua Sun ${ }^{1, *}$, Yuyan Wang ${ }^{1, *}$ (D) and Shuiye Niu ${ }^{2}$ \\ 1 School of Management Science and Engineering, Shandong University of Finance and Economics, \\ Jinan 250014, China; kelei.xue@gmail.com \\ 2 School of Innovation and Entrepreneurship, Shandong University, Qingdao 266237, China; \\ blueanglelove@126.com \\ * Correspondence: nksungh@163.com (G.S.); wangyuyan1224@126.com (Y.W.)
}

\section{check for} updates

Citation: Xue, K.; Sun, G.; Wang, Y.; Niu, S. Optimal Pricing and Green Product Design Strategies in a Sustainable Supply Chain Considering Government Subsidy and Different Channel Power Structures. Sustainability 2021, 13, 12446. https://doi.org/10.3390/ su132212446

Academic Editors: Cristina Cazan and Shauhrat S. Chopra

Received: 18 September 2021

Accepted: 10 November 2021

Published: 11 November 2021

Publisher's Note: MDPI stays neutral with regard to jurisdictional claims in published maps and institutional affiliations.

Copyright: (c) 2021 by the authors. Licensee MDPI, Basel, Switzerland. This article is an open access article distributed under the terms and conditions of the Creative Commons Attribution (CC BY) license (https:/ / creativecommons.org/licenses/by/ $4.0 /)$.

\begin{abstract}
Green product design is a vital measure to support sustainable development in a circular economy era. This paper studies the multi-product pricing and green product design strategies under different supply chain structures and government subsidy strategies. Considering different channel leadership, we establish the centralized (C), manufacturer-led (MS), and retailer-led (RS) supply chain models, respectively. By applying a game-theoretical approach, corresponding equilibrium pricing, green product design, and government subsidy decisions under different supply chain structures are obtained. Through comparison and numerical analysis, we find that: (1) the different subsidy strategies of the government have an important impact on green product development. When the government provides a uniform subsidy strategy, a $R S$ supply chain can bring greener product, more market demands, more profit, and more social welfare; (2) when the government provides a differentiated subsidy strategy, $M S$ and $R S$ supply chain structures can bring greener product and more market demand than the centralized supply chain. They can also bring the same social welfare and the same product to the green design level. However, the MS supply chain structure can bring more profit for the firm; (3) the consumers' green awareness positively impacts the design and development of green product. Therefore, it is beneficial for the firm to adopt reasonable measures to boost the environmental awareness of consumers in order to realize the sustainable development of our society.
\end{abstract}

Keywords: green product design; multi-product pricing; government subsidy; channel power structures

\section{Introduction}

Sustainable supply chain management has received increasing attention in a circular economy era, driven by environmental responsibilities, consumer pressures, government regulations, and competitor pressures [1]. Many scholars study green product design, remanufacturing, and reverse logistics, etc., to promote sustainable supply chain management [2]. Green product design plays a crucial role in maximizing a firm's profit and minimizing environmental impact. Green design provides many obvious benefits for enterprises, including increasing the possibility of additional sales, increasing consumers' satisfaction, increasing social responsibility and environmental performance, abiding by current and future regulations, and improving brand reputation. Nowadays, a growing number of consumers are inclined to buy environmentally friendly and pollution-free green products [3]. In a global survey conducted by Accenture, more than $80 \%$ of interviewees show their high green preference when making purchasing choices (Available at: https://newsroom.accenture.com/article_display.cfm?article_id=4801, accessed on 11 July 2021). Carbon Trust surveys also show that nearly one-fifth of customers prefer green products even though these products are more expensive than regular ones (Available 
at: http:/ /www.carbontrust.com/news/2011/07/ consumer-dem-and-for-lower-carbonlifestyles-is-putting-pressure-on-business, accessed on 11 July 2021). Consumers' green purchasing behaviors are directly related to consumers' environmental awareness (CEA), which is a critical market-driven factor for purchasing options [4].

Our research is mainly motivated by the following enterprises' cases. Many enterprises are expanding their market share by launching green versions of traditional brown products, which are very similar in all aspects except for the green characteristic. For example, in the automotive industry, Toyota provides hybrid electric versions of vehicles (e.g., Camry, Carola, Prius) which are eco-friendly, in addition to traditional models that use gasoline. Volkswagen promotes and develops plug-in hybrid electric vehicles (e.g., Passat, Audi A3, A6, Q5, Q7), which have large battery capacity and are more eco-friendly than the traditional models. The Audi brand also provides the pure electric version of vehicles in the Q2 model (i.e., Q2L e-tron), which can be regarded as the most environmentally friendly car compared with the above two models. Similar situations can be observed in other industries. For example, almost all home appliances brands (e.g., Siemens, Haier, Gree) produce green versions of products similar to traditional products in all aspects, but differ in energy consumption. In the apparel industry, many large brands (e.g., H\&M, Zara, Nike) provide green versions of clothing, which are similar to ordinary clothing in all aspects, but are made of $100 \%$ organic fibers. Moreover, enterprises often have different channel powers and are in different positions in the supply chain. In the previous examples, Toyota, Siemens, and Haier have more channel powers than their retailers. On the contrary, H\&M, Zara, and Nike have channel leadership compared with their suppliers. Another similar example is Suning. Suning, a giant retailer, supports and cooperates with its upstream manufacturer (e.g., ANGEL) to improve product green level (Available at: http:/ /www.cinn.cn/gysj/201804/t20180416_180606_wap.html, accessed on 11 July 2021).

In reality, many governments, such as China, America, India, etc., have provided various subsidy policies to promote green innovation and sustainable development. For example, in 2012, China decided to arrange financial subsidy at $13 \%$ of the sales price (CNY 26.5 billion in total) to promote home appliances (e.g., air conditioners, refrigerators, washing machines, etc.) to meet energy-saving standards. In America, consumers who purchased new energy vehicles will enjoy tax credits ranging from USD 2500 to 7500. Meanwhile, China has also launched its series of new energy vehicle subsidy policies. In 2019, China's subsidy standard for pure electric vehicles with a driving range of more than $400 \mathrm{~km}$ was CNY 25,000 per vehicle. The India Ministry of Power government subsidized the purchasing of LED lightbulbs in the country through the UJALA program (Available at: http:/ /www.ujala.gov.in/, accessed on 11 July 2021). The underlying rationale is still unclear on the government subsidy associated with the expected behavior from the enterprise.

Based on the firms' cases as mentioned above in practice, we propose the following research questions:

Research Question 1: With the coexistence of the regular and green products, how should the firm formulate reasonable pricing and green product design strategies when considering CEA?

Research Question 2: What effects are the different government subsidy strategies, i.e., uniform subsidy and differentiated subsidy, having on the firm's multi-product pricing and green product design?

Research Question 3: At the supply chain level, if it exists, what is the optimal channel structure for the firm from the firm's profit and total social welfare?

Our research problem is related to the literature about multi-product pricing, green product design, and government policy under sustainable supply chains. Our paper is closely related to Agi and Yan [5], Hong et al. [6], and Bian et al. [7]. Agi and Yan [5] investigate pricing and positioning strategies for brown and green products under different channel power structures. However, their work does not involve the issues of green product design and government subsidy. Hong et al. [6] investigate the effects of tax regulation, 
consumers' reference behaviors, and CEA on the green product design and competitive pricing strategies under both manufacturer-led and retailer-led supply chain structures. The main difference is that our study considers two types of consumer subsidy strategies (not tax regulation) from the government and investigates their effects on the green product design. We also find that manufacturer-led and retailer-led supply chains have the same social welfare when the government provides a differentiated subsidy strategy, which is different from their research. Bian et al. [7] is one of the few studies to explore the impact of the environmental subsidy policies (i.e., manufacturer subsidy vs. consumer subsidy) from the government on green product design. Unlike their study, our paper considers the other two types of consumer subsidies: uniform subsidy and differentiated subsidy. However, our paper pays more attention to the game relationship between the supply chain members and explores how it affects the green product design and multi-product pricing strategies.

To answer the above research questions and fill these research gaps, we investigate the multi-product pricing and green product design strategies in a sustainable supply chain, considering the government's different subsidy strategies and different channel power structures. Firstly, we construct the consumer demand function by the utility model. Afterward, considering different channel powers and the government's two types of subsidy strategies, we establish the Stackelberg game models in the centralized, manufacturer-led, and retailer-led supply chain, respectively. By applying a game-theoretical approach, corresponding equilibrium pricing, green product design, and government subsidy decisions under different supply chain structures are obtained. Finally, we compare the optimal decisions, profits of the supply chain, and total social welfare under different channel power structures and subsidy strategies of the government.

To sum up, our main contributions in this paper are as follows.

1. To the best of our knowledge, our paper is one of the first to investigate the joint decisions of pricing and green product design strategies considering the coexistence of the regular product and green product under different channel power structures and subsidy strategies of the government.

2. Our paper considers the government's two types of consumer subsidy strategies: uniform subsidy and differentiated subsidy, which are seldom studied by relevant scholars. Under the differentiated subsidy strategy, the government can decide its optimal subsidy based on different supply chain structures to maximize the total social welfare consisting of monetary and environmental welfare.

3. Under the changing operational environment, the optimal decisions and profits of the supply chain and the optimal government subsidies and total social welfare under different supply chain structures are compared and analyzed to derive more conclusions and managerial implications.

The rest of the study is structured as follows. First, we give the literature review in Section 2. Then, in Section 3, we describe the problem and the model. In Section 4, we formulate the optimization problems of the supply chain and the government and give the corresponding equilibrium decisions under three different power structures. In Section 5 , we compare the optimal decisions of the supply chain and the government under two types of government subsidy strategies. Furthermore, through the numerical analysis method, more managerial implications are derived. Finally, Section 6 concludes the study and presents future research directions.

\section{Literature Review}

Our paper is closely related to three streams of literature: multi-product pricing, green product design, and government policy in sustainable supply chains. This section reviews literature relevant to each stream and highlights the differences between the existing research and our work. 


\subsection{Multi-Product Pricing}

Multi-product pricing is one of the most important topics drawing attention from relevant scholars from green supply chain management [8-18]. Our paper considers the pricing scenario with the coexistence of the regular and green products. In the following, we mainly review papers related to this scenario.

Su et al. [8] investigated the green product's pricing and environmental quality design problems. They derived conditions under which Market Segmentation strategy (two products are offered) or Mass Marketing strategy (a single product is offered) is adopted by the firm. By establishing and solving a two-product optimization model, $\mathrm{Li}$ and $\mathrm{Li}$ [9] also studied green market segmentation and their pricing decisions, where the government subsidy regulation is considered in their work. Under consumers' market segmentation and different channel power structures, Agi and Yan [5] investigated pricing and positioning strategies for brown and green products and examined the coordination mechanisms in two decentralized supply chains.

Some scholars investigate the pricing problem in a competitive supply chain. $\mathrm{Li}$ and $\mathrm{Li}[10]$ considered the competition at the supply chain level and examined how the sustainability competition influences product sustainability. Deng et al. [12] also considered the competition between two supply chains and explored how horizontal and vertical competition affect product sustainability and supply chain profits. The above two studies both assume that the consumers' demand function is sustainability-sensitive. From the economy and environment perspective, Sim et al. [13] investigated the effects of supply chain competition on abatement efforts and eco-friendly social welfare. Their results show that the most efficient market structures were maybe not efficient from a broader perspective. Under an eco-label policy, Gao et al. [14] studied the pricing and coordination problem in a dual-channel green supply chain.

There are also scholars exploring the effects of CEA on the optimal pricing strategies. Using a multi-product newsvendor model, Zhang et al. [15] investigated the green product pricing problem and explored the effects of CEA on order quantities and channel coordination. Considering CEA and non-green product reference, Hong et al. [16] investigated the green product pricing problem under three scenarios: single-product pricing, dualproduct competition, and an asymmetric information case. Their analysis results show that a differential pricing strategy should be adopted when facing consumers with different buying behaviors. Under three different market scenarios, Zhang et al. [17] studied the introduction problem of green products and strategic pricing and examined how the above decisions are affected by CEA.

Unlike our paper, all the above papers do not consider the investment decisions of the supply chain members for green product design or development for environmental sustainability under different supply chain channel structures.

\subsection{Green Product Design}

Green product design is an effective method for realizing a circular economy and has been widely studied by numerous scholars from various perspectives [18-28]. In the following, we mainly review papers that study green product design issues from the perspectives of cooperation, competition, and government regulation.

Some scholars study the cooperation contracts or strategies which are used to enhance green product design. Considering two types of cost-sharing contracts, Ghosh and Shah [19] explored the coordination issues and demonstrated the impacts of cost-sharing contracts on product greening levels, prices, and profits within the supply chains. Hong and Guo [20] studied three types of coordination contracts, i.e., price-only, green-marketing cost sharing, and two-part tariff contracts. They found that cooperation among partners can help the supply chain realize environmental improvements. Dong et al. [21] studied who should lead and invest in green product development (GPD) in a supply chain consisting of one manufacturer and one retailer. By developing a two-period model, they found that the products are greener when the manufacturer invests in GPD, and the manufacturer earns 
more. In a decentralized supply chain, Li et al. [22] considered two types of cooperative contracts: contracting designing (CD) format and contracting marketing format (CM), and explored how to select an appropriate cooperative contract to boost product greening level.

Some other scholars investigate the effects of competition on green product design strategies. Zhu and He [23] explored the firms' green product design issues under supply chains competition. They addressed how the green product types, the types of competition (price competition or greenness competition) affect the "greenness" of products. In the case of considering consumer returns, Guo et al. [24] investigated how the greenness competition affects green product design in fashion apparel. Considering different channel powers, Ma et al. [25] explored how the competition between upstream manufacturers and supply chain structure affects the green manufacturing level. Considering the competition between the upstream firms of the supply chain, Du et al. [26] also explored the competition between the upstream manufacturers and how this type of competition affects the green product design strategy adoption and pricing strategy. Unlike our paper, none of the above literature involves the issue of the government subsidy and different channel structures.

\subsection{Government Policy}

Scholars are also exploring the effects of government regulation or subsidy on green product design strategies [29-38]. Cai et al. [32] explored three types of environmental taxes: linear tax, constant tax, and zero tax, and examined how the producer's optimal DfE (Design for Environment) level could be influenced by them. Yalabik and Fairchild [35] studied how the regulatory penalty and retail competition influence the investment in emission reduction. Considering the extended producer responsibility (EPR) policy, Subramanian et al. [36] investigated how the EPR regulation affects durable product design. Their study took into account the tax policy in green product design. Considering consumers' reference behaviors, Hong et al. [6] investigated the effects of tax regulation, consumers' reference behaviors, and CEA on the green product design and pricing strategies. Different from their study, we consider the government's two different subsidy strategies and investigate their effects on green product design. In the textiles and apparel supply chains, Shen et al. [37] explored the effects of environmental taxes on green technology adoption. In a research joint venture (RJV), Chen et al. [38] endogenized government subsidy and explored the effects of two types of subsidy and two forms of RJV formation on the level of sustainability innovation. Bian et al. [7] considered two types of government technology subsidy policies: consumer and manufacturer subsidies, and explored the effects of different subsidy policies on the manufacturer's green investment decisions. Unlike our study, the papers mentioned above do not consider the effects of a differentiated subsidy strategy of the government on the green product design under different channel power structures.

\subsection{Summary}

In order to show the novelty of this article more clearly, we provide Table 1 to present the main differences between our work and related studies, which can be summarized in three points. Firstly, most papers on pricing do not consider green product design and government subsidy, or they do not explore the impacts of different channel power structures on the green product design. Secondly, most papers on green product design do not involve the issues of the government subsidy and different channel structures. Thirdly, few scholars have studied the government's two types of consumer subsidy strategies: uniform subsidy and differentiated subsidy. To fill the above research gaps, we explore the multi-product pricing and green product design strategies in a sustainable supply chain, considering the government's different subsidy strategies and channel power structures.

Moreover, our paper adopts the game-theoretical approach. The reasons are as follows. Most relevant scholars (refer to Table 1) adopt a game-theoretical approach to model related research problems. A few scholars use optimization or other modeling methods. For example, Zhang et al. [15] used a newsvendor model method in a random demand 
environment. Hong et al. [16] and Cai et al. [32] adopted an optimization modeling method considering a single decision-maker. Our paper examines the strategic interactions among multiple decision-makers. Therefore, we adopt a game-theoretical approach to model and analyze our problem.

Table 1. Main differences between our work and related studies.

\begin{tabular}{|c|c|c|c|c|c|c|c|c|}
\hline \multirow{3}{*}{ Articles } & \multirow{3}{*}{$\begin{array}{l}\text { Channel } \\
\text { Structure }\end{array}$} & \multirow{3}{*}{ Modeling Method } & \multicolumn{4}{|c|}{ Issues Involved } & \multicolumn{2}{|c|}{ Decision Variables } \\
\hline & & & \multicolumn{2}{|c|}{ Government Policy } & \multirow{2}{*}{ CEA } & \multirow{2}{*}{ Product Type } & \multirow{2}{*}{$\begin{array}{c}\text { Green } \\
\text { Design }\end{array}$} & \multirow{2}{*}{ Price } \\
\hline & & & Subsidy & Tax & & & & \\
\hline $\mathrm{Li}$ and $\mathrm{Li}$ [9] & One firm & Game & $\sqrt{ }$ & & $\sqrt{ }$ & Regular + Green & & $\sqrt{ }$ \\
\hline $\mathrm{Li}$ and $\mathrm{Li}[10]$ & Two chains & Game & & & & Green & $\sqrt{ }$ & \\
\hline Agi and Yan [5] & $M S, R S, C$ & Game & & & $\sqrt{ }$ & Regular + Green & & $\sqrt{ }$ \\
\hline Deng et al. [12] & Two chains & Game & & & & Green & $\sqrt{ }$ & \\
\hline Sim et al. [13] & Two chains & Game & & & & Green & $\sqrt{ }$ & $\sqrt{ }$ \\
\hline Gao et al. [14] & Dual-channel & Game & $\sqrt{ }$ & & & Green & & $\sqrt{ }$ \\
\hline Zhang et al. [15] & $M S, C$ & Newsvendor & & & $\sqrt{ }$ & Regular + Green & & $\sqrt{ }$ \\
\hline Hong et al. [16] & Two firms & Optimization, Bayes & & & $\sqrt{ }$ & Regular + Green & & $\sqrt{ }$ \\
\hline Zhang et al. [17] & $M S, C$ & Game & $\sqrt{ }$ & & $\sqrt{ }$ & Regular + Green & & $\sqrt{ }$ \\
\hline Ghosh and Shah [19] & $M S, C$ & Game & & & $\sqrt{ }$ & Green & $\sqrt{ }$ & $\sqrt{ }$ \\
\hline Hong and Guo [20] & $M S, C$ & Game & & & $\sqrt{ }$ & Green & $\sqrt{ }$ & $\sqrt{ }$ \\
\hline Dong et al. [21] & MS & Two-period & & & $\sqrt{ }$ & Regular + Green & $\sqrt{ }$ & $\sqrt{ }$ \\
\hline Zhu and He [23] & $M S, C$ & Game & & & $\sqrt{ }$ & Green & $\sqrt{ }$ & $\sqrt{ }$ \\
\hline Guo et al. [24] & $M S$ & Multi-methodological & & & $\sqrt{ }$ & Green & $\sqrt{ }$ & $\sqrt{ }$ \\
\hline Du et al. [26] & MS & Game & & & $\sqrt{ }$ & Green & $\sqrt{ }$ & $\sqrt{ }$ \\
\hline Hong et al. [6] & $M S, R S$ & Game & & $\sqrt{ }$ & $\sqrt{ }$ & Regular + Green & $\sqrt{ }$ & $\sqrt{ }$ \\
\hline Shen et al. [37] & $M S$ & Game & & $\sqrt{ }$ & & Green & $\sqrt{ }$ & $\sqrt{ }$ \\
\hline Cai et al. [32] & One firm & Optimization & & $\sqrt{ }$ & & Green & $\sqrt{ }$ & $\sqrt{ }$ \\
\hline Bian et al. [7] & $M+G$ & Game & $\sqrt{ }$ & & $\sqrt{ }$ & Green & $\sqrt{ }$ & $\sqrt{ }$ \\
\hline Our paper & $M S, R S, C$ & Game & $\sqrt{ }$ & & $\sqrt{ }$ & Regular + Green & $\sqrt{ }$ & $\sqrt{ }$ \\
\hline
\end{tabular}

MS: Manufacturer-led Supply chain; RS: retailer-led supply chain; C: centralized supply chain; $\mathrm{G}+\mathrm{M}$ : manufacturer and government; Regular + Green: regular (non-green) and green products; CEA: consumers' environmental awareness.

\section{Model Descriptions}

Consider a decentralized supply chain that consists of a manufacturer and a retailer. The manufacturer produces two types of products: regular product (labeled as product 1 ) and green product (labeled as product 2). Green product can be regarded as green versions of regular product with the same or similar product function. For example, Toyota and Volkswagen simultaneously provide traditional fuel vehicles and hybrid electric vehicles to the market in the same models (e.g., Camry, Carola, Passat, Audi A3). Compared with the regular product, the green product is designed to have less environmental impact at different stages of its life cycle, including manufacturing, usage, and recycling. We use $e$ $(0<e<1)$ to denote the green design level of the green product. The retailer wholesales two types of products from the manufacturer and sells them to consumers in the market.

The manufacturer needs to invest in research and development (R\&D) costs to develop environmentally friendly products. The amount of capital investment is $\frac{1}{2} k e^{2}$, where $k>0$ denotes the R\&D cost coefficient for the green product. This quadratic cost function is widely used in relevant literature, e.g., $[21,23,39,40]$. The production cost per unit of green product is $c_{2}=c_{1}+c$, where $c_{1}$ is the production cost per unit of the regular product. Then $c>0$ can be regarded as the increase in production cost of the green product compared with the regular product. In general, the production of the green product is usually more expensive than that of the regular product [41,42]. For example, the production cost of coffee with environmentally friendly production technology has increased by 30\% (Available at: http:/ / www.triplepundit.com/2014/11/economics-sustainable-coffee-

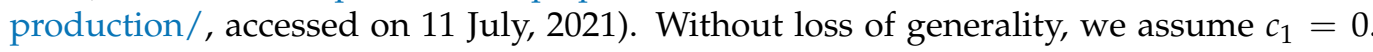
When $c_{1}=0$, parameter $c$ can be regarded as the production cost of the green product.

Consumers are environmentally conscious and homogeneous in obtaining environmental utility from the green product, but are heterogeneous in terms of their evaluations of the functional attributes of products $[6,16,20]$. We use $V$ to denote the utility of consumers obtaining from the functional attribute of the product. We assume $V$ is uniformly 
distributed in the interval $[0,1]$ and its probability density function (PDF) and cumulative distribution function (CDF) are $f(\cdot)$ and $F(\cdot)$, respectively $[43,44]$. The function formulas of $f(\cdot)$ and $F(\cdot)$ are given by Equation (1). The utility of consumers purchasing the regular product is $U_{1}=V-p_{1}$, where $p_{1}$ is the retail price of the regular product.

$$
\left\{\begin{array}{l}
f(x)=1 \\
F(x)=x
\end{array}, x \text { is the realized value of } V .\right.
$$

The utility of a consumer deriving from the green product's functional attribute is $\theta V$, where $\theta>1$ indicates that consumers have a higher willingness to pay for the functional attribute of the green product [16]. In reality, generally speaking, the green version of the regular product usually has a higher functional attribute than the regular product, e.g., air conditioner, etc. Then, we assume that $\theta>1$. We also solve our models when $\theta<1$. We find that our main findings and managerial insights are robust. The consumer can also homogeneously derive utility from the environmental attribute of the green product. The environmental utility is assumed to be $\lambda e$ [45], where $\lambda>0$ is the consumers' preference coefficient for the green product's greenness and can also indicate the level of CEA [46]. In practice, the government can provide subsidies to the consumers who buy green product. The utility of consumers purchasing the green product is $U_{2}=\theta \mathrm{V}-p_{2}+s+\lambda e$, where $s$ denotes the government subsidy to the consumer who purchases a green product and $p_{2}$ is the retail price of the green product. We do not consider the heterogeneity of consumers in purchasing quantity, and then we assume one consumer purchases at most one unit of the product. The market size is normalized to one.

In the market, consumers decide which type of product to buy by comparing their utilities. The consumers buy the regular product under the condition of $U_{1} \geq U_{2}, U_{1} \geq 0$, i.e., $p_{1} \leq V \leq \frac{p_{2}-p_{1}-s-\lambda e}{\theta-1}$. The consumers buy the green product if and only if $U_{2} \geq U_{1}$, $U_{2} \geq 0$, i.e., $\max \left\{\frac{p_{2}-s-\lambda e}{\theta}, \frac{p_{2}-p_{1}-s-\lambda e}{\theta-1}\right\} \leq V \leq 1$. Like Hong et al. [6] and Hong et al. [16], we only consider the situation where regular and green products are presented in the market. Let $q_{1}$ and $q_{2}$ denote the number of consumers buying the regular and green products, respectively. Then, the market demands for regular and green products are

$$
\begin{gathered}
q_{1}=\int_{p_{1}}^{\frac{p_{2}-p_{1}-s-\lambda e}{\theta-1}} d F(x)=\frac{p_{2}-\theta p_{1}-s-\lambda e}{\theta-1}, \\
q_{2}=\int_{\frac{p_{2}-p_{1}-s-\lambda e}{\theta-1}}^{1} d F(x)=1-\frac{p_{2}-p_{1}-s-\lambda e}{\theta-1} .
\end{gathered}
$$

Accordingly, the profits of the manufacturer, retailer, and supply chain are

$$
\begin{gathered}
\pi_{m}\left(w_{1}, w_{2}, e\right)=w_{1} q_{1}+\left(w_{2}-c\right) q_{2}-\frac{1}{2} k e^{2}, \\
\pi_{r}\left(p_{1}, p_{2}\right)=\left(p_{1}-w_{1}\right) q_{1}+\left(p_{2}-w_{2}\right) q_{2}, \\
\pi_{s c}\left(p_{1}, p_{2}, e\right)=p_{1} q_{1}+\left(p_{2}-c\right) q_{2}-\frac{1}{2} k e^{2} .
\end{gathered}
$$

In Equation (4), the first two terms are the manufacturer's profits from selling the regular and green products to the retailer; the third term is R\&D investment for the green product. In Equation (5), the first and second terms denote the retailer's profits from selling the regular and green products to the consumers. Equation (6) is the sum of Equations (4) and (5).

In addition, we also consider the impacts of supply chain decisions on entire social welfare. Similar to $\mathrm{Li}$ and $\mathrm{Li}$ [9], the entire social welfare can be given by

$$
S W=\pi_{s c}+C S-s q_{2}-t\left(q_{1}+(1-e) q_{2}\right) .
$$


In Equation (7), the first term $\pi_{s c}$ is the profit of the total supply chain; the second term $C S$ is consumer's surplus; the third term $s q_{2}$ is the total subsidy given by the government; the fourth term $t\left(q_{1}+(1-e) q_{2}\right)$ is the negative impacts (e.g., carbon emission) of the regular and green products on the environment in the entire life cycle, where $t$ denotes the negative environmental impact coefficient. The first three terms of Equation (7) are monetary welfare, and the last term is environmental welfare. The consumer's surplus CS can be given by

$$
C S=\int_{p_{1}}^{\frac{p_{2}-p_{1}-s-\lambda e}{\theta-1}}\left(x-p_{1}\right) d F(x)+\int_{\frac{p_{2}-p_{1}-s-\lambda e}{\theta-1}}^{1}\left(\theta x-p_{2}+s+\lambda e\right) d F(x)
$$

To ensure that the mathematical model is solvable and avoid trivial outcomes, we make the following assumptions: $2 k(c-s)>\lambda^{2}, \theta-1>c$ and $k(\theta-1)>2 \lambda(2 t+\lambda)$. For notational convenience, we use superscript "*", " $C$ ", " $M S^{\prime \prime}$ and " $R S^{\prime \prime}$ to denote "optimal", "centralized supply chain", "manufacturer-led supply chain" and "retailer-led supply chain", respectively. Subscript " $m$ ", " $r$ " and " $s c$ " refer to "manufacturer", "retailer" and "supply chain", respectively. The model parameters and other notations used in this paper are concluded in Table 2.

Table 2. The notations used in this paper.

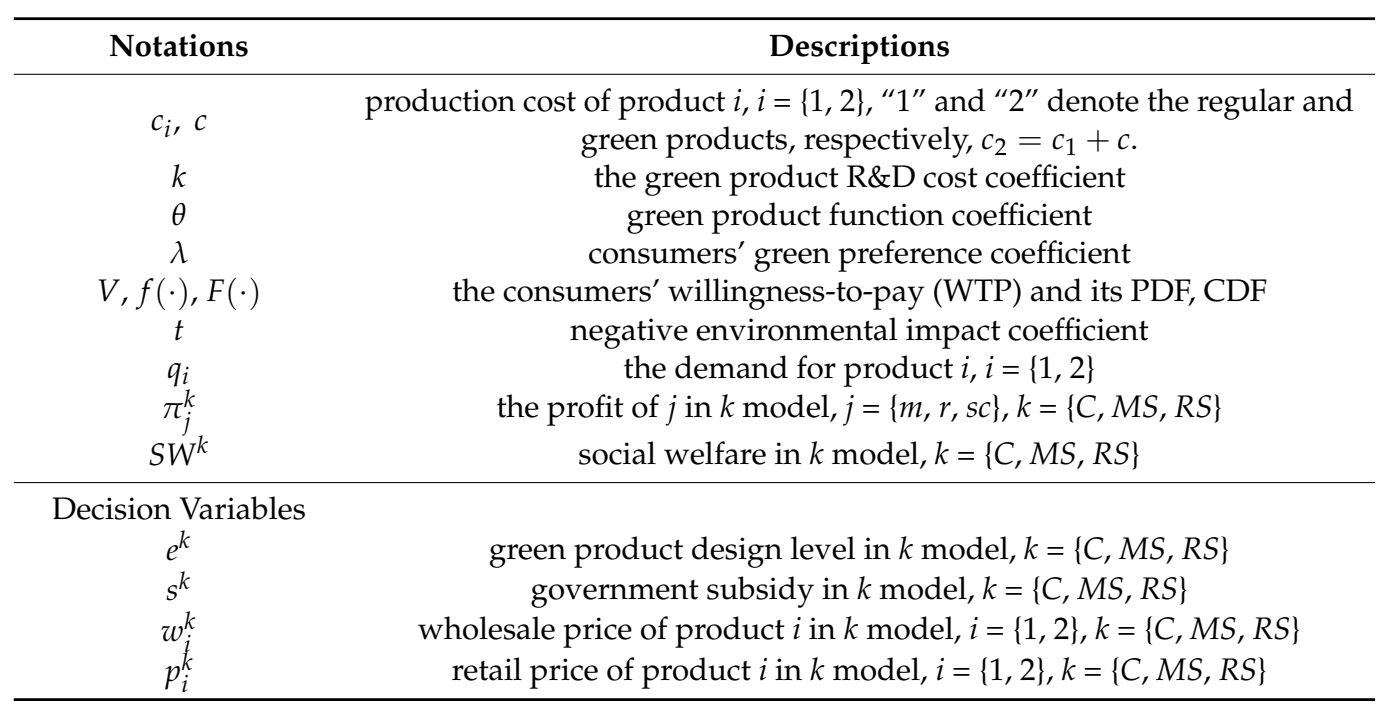

\section{Model Analyses}

In this section, considering different channel powers, centralized supply chain $(C)$, manufacturer-led supply chain $(M S)$, and retailer-led supply chain $(R S)$ models are established. The game-theoretical method is used to analyze the three models. We also consider the scenario where the government can provide two different types of subsidy strategies, i.e., the uniform subsidy of the government and differentiated subsidy of the government. In each subsidy strategy of the government, we derive the equilibrium decisions of the supply chain and government.

\subsection{Centralized Supply Chain (C) Model}

We first consider the scenario where the manufacturer and the retailer act as one company. They make decisions from the perspective of the whole supply chain. We call this scenario a centralized supply chain $(C)$ model. In the $C$ model, the supply chain decides the green design level of the green product and the prices of regular and green products. Therefore, the supply chain's optimization problem can be formulated as

$$
\max _{p_{1}, p_{2}, e} \pi_{s \mathcal{C}}^{C}\left(p_{1}, p_{2}, e\right)=p_{1} q_{1}+\left(p_{2}-c\right) q_{2}-\frac{1}{2} k e^{2}
$$


where $q_{1}$ and $q_{2}$ are given by Equations (2) and (3). Solving the supply chain's optimization problem, we can derive the following Lemma 1.

Lemma 1. In the $C$ model, the optimal retail prices and demands of the regular and green products, the optimal green product design level are $p_{1}^{C *}=\frac{1}{2}, p_{2}^{C *}=\frac{2 k(\theta-1)(c+s+\theta)-(1+2 c) \lambda^{2}}{4 k(\theta-1)-2 \lambda^{2}}, q_{1}^{C *}=$ $\frac{2 k(c-s)-\lambda^{2}}{4 k(\theta-1)-2 \lambda^{2}}, q_{2}^{C *}=\frac{k(s+\theta-c-1)}{2 k(\theta-1)-\lambda^{2}}$, and $e^{C *}=\frac{(s+\theta-c-1) \lambda}{2 k(\theta-1)-\lambda^{2}}$.

The proofs of all Lemmas, Corollaries, Theorems, and Propositions are in Appendix A. According to Lemma 1, the following corollary can be obtained.

Corollary 1. In the C model,

(1) for the regular product: $\frac{\partial q_{1}^{\mathcal{C}}}{\partial k}>0, \frac{\partial q_{1}^{\mathcal{C}}}{\partial c}>0, \frac{\partial q_{1}^{\mathcal{C}}}{\partial \theta}<0, \frac{\partial q_{1}^{\mathcal{C}}}{\partial \lambda}<0, \frac{\partial q_{1}^{\mathcal{C} *}}{\partial s}<0$;

(2) for the green product: $\frac{\partial p_{2}^{C *}}{\partial k}<0, \frac{\partial p_{2}^{\mathcal{C}}}{\partial c}>0, \frac{\partial p_{2}^{\mathcal{C}}}{\partial \theta}>0, \frac{\partial p_{2}^{\mathcal{C}}}{\partial \lambda}>0, \frac{\partial p_{2}^{C *}}{\partial s}>0$;

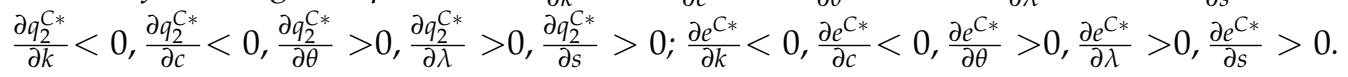

According to Lemma 1 and Corollary 1, in the $C$ model, no matter how the operational environment changes, the retail price of the regular product is constant. The market demand for the regular product increases in the green product R\&D cost coefficient, green product production cost, and decreases in consumers' green product function coefficient, consumers' green preference coefficient, and government subsidy. In contrast, for the green product, the retail price, market demand, and green design level decrease in green product $R \& D$ cost coefficient, and increase in consumers' green product function coefficient, consumers' green preference coefficient, and government subsidy.

Now we turn to the government's problem. The government's goal is to maximize the entire social welfare. The government can provide two subsidy strategies, i.e., the uniform subsidy of government and differentiated subsidy of government. Under the uniform subsidy strategy, the government provides the same subsidy in the $C, M S$, and RS models. Under the differentiated subsidy strategy, the government provides different subsidies in different models. In the following, we consider the scenario where the government provides the differentiated subsidy. Under this scenario, the government first decides the optimal subsidy policy for the green product. Then, it is followed by the supply chain's optimization problem. The government's decision-making problem is formulated as

$$
\max _{s} S W^{\mathrm{C}}(s)=\pi_{s c}^{\mathrm{C} *}+C S^{\mathrm{C} *}-s q_{2}^{\mathrm{C} *}-t\left(q_{1}^{\mathrm{C} *}+(1-e) q_{2}^{\mathrm{C} *}\right) .
$$

Substituting the optimal decisions given by Lemma 1 into Equation (10), we can obtain the optimal subsidy by solving the government's optimization problem. We use superscript " $D$ " to differentiate the optimal decisions under the differentiated subsidy strategy of the government.

Theorem 1. Under the differentiated subsidy strategy and C model, the government's optimal subsidy that maximizes the total social welfare is

$$
s^{D C *}=\frac{(\theta-1-c)(k(\theta-1)+2 t \lambda)}{k(\theta-1)-\lambda(2 t+\lambda)}
$$

From Theorem 1, we can derive the following Corollary 2.

Corollary 2. $\frac{\partial s D C *}{\partial k}<0, \frac{\partial s D C *}{\partial c}<0, \frac{\partial s D C *}{\partial \lambda}>0, \frac{\partial s D C *}{\partial t}>0$.

When the government adopts a differentiated subsidy strategy, the increases in green product $R \& D$ cost coefficient and green product production cost lead to the decrease in 
the optimal government subsidy. In contrast, the increases in consumers' green preference coefficient and negative environmental impact coefficient lead to the increase in the optimal government subsidy.

Substituting the optimal government subsidy given by Equation (11) into the optimal supply chain decisions given by Lemma 1, we can get Lemma 2 as follows.

Lemma 2. Under the differentiated subsidy strategy and C model, the optimal retail prices and demands of the regular and green products, the optimal green product design level are $p_{1}^{D C *}=\frac{1}{2}$, $p_{2}^{D C *}=\frac{k(\theta-1)(2 \theta-1)-(1+2 c) \lambda(2 t+\lambda)}{2 k(\theta-1)-2 \lambda(2 t+\lambda)}, q_{1}^{D C *}=\frac{1}{2}+\frac{k(1+c-\theta)}{k(\theta-1)-\lambda(2 t+\lambda)}, q_{2}^{D C *}=\frac{k(\theta-1-c)}{k(\theta-1)-\lambda(2 t+\lambda)}$, $e^{D C *}=\frac{(\theta-1-c) \lambda}{k(\theta-1)-\lambda(2 t+\lambda)}$.

\subsection{Manufacturer-Led Supply Chain (MS) Model}

In this subsection, we consider the scenario where the manufacturer has more channel power than the retailer. We call this scenario a manufacturer-led supply chain (MS) model, in which the manufacturer acts as the Stackelberg game leader while the retailer acts as the follower. In the MS model, the manufacturer first decides the green product design level and the wholesale prices of the regular and green products. Then, the retailer decides the retail prices of the regular and green products. The MS model is formulated as

$$
\left\{\begin{array}{c}
\max _{w_{1}, w_{2}, e} \pi_{m}^{M S}\left(w_{1}, w_{2}, e\right)=w_{1} q_{1}+\left(w_{2}-c\right) q_{2}-\frac{1}{2} k e^{2} \\
p_{1}^{*} \text { and } p_{2}^{*} \text { are derived from solving the following problem, } \\
\max _{p_{1}, p_{2}} \pi_{r}^{M S}\left(p_{1}, p_{2}\right)=\left(p_{1}-w_{1}\right) q_{1}+\left(p_{2}-w_{2}\right) q_{2}
\end{array}\right.
$$

where $q_{1}$ and $q_{2}$ are given by Equations (2) and (3). Solving the MS model, we can derive Lemma 3 as follows.

Lemma 3. In the MS model, the optimal wholesale prices, retail prices, and demands of the regular and green products, and the optimal green product design level are $w_{1}^{M S *}=\frac{1}{2}, w_{2}^{M S *}=$ $\frac{4 k(\theta-1)(c+s+\theta)-(1+2 c) \lambda^{2}}{8 k(\theta-1)-2 \lambda^{2}}, p_{1}^{M S *}=\frac{3}{4}, p_{2}^{M S *}=\frac{4 k(\theta-1)(c+3(s+\theta))-(3+4 c) \lambda^{2}}{16 k(\theta-1)-4 \lambda^{2}}, q_{1}^{M S *}=\frac{4 k(c-s)-\lambda^{2}}{4\left(4 k(\theta-1)-\lambda^{2}\right)}$, $q_{2}^{M S *}=\frac{k(s+\theta-1-c)}{4 k(\theta-1)-\lambda^{2}}, e^{M S *}=\frac{(s+\theta-1-c) \lambda}{4 k(\theta-1)-\lambda^{2}}$.

According to Lemma 3, the following Corollary 3 can be obtained.

Corollary 3. In the MS model,

(1) for the regular product: $\frac{\partial q_{1}^{M S *}}{\partial k}>0, \frac{\partial q_{1}^{M S *}}{\partial c}>0, \frac{\partial q_{1}^{M S *}}{\partial \theta}<0, \frac{\partial q_{1}^{M S *}}{\partial \lambda}<0, \frac{\partial q_{1}^{M S *}}{\partial s}<0$;

(2) for the green product: $\frac{\partial w_{2}^{M S *}}{\partial k}<0, \frac{\partial w_{2}^{M S *}}{\partial c}>0$, $\frac{\partial w_{2}^{M S *}}{\partial \lambda}>0, \frac{\partial w_{2}^{M S *}}{\partial s}>0$; $\frac{\partial p_{2}^{M S *}}{\partial k}<0, \frac{\partial p_{2}^{M S *}}{\partial c}>0, \frac{\partial p_{2}^{M S *}}{\partial \lambda}>0, \frac{\partial p_{2}^{M S *}}{\partial s}>0 ; \frac{\partial q_{2}^{M S *}}{\partial k}<0, \frac{\partial q_{2}^{M S *}}{\partial c}<0, \frac{\partial q_{2}^{M S *}}{\partial \theta}>0, \frac{\partial q_{2}^{M S *}}{\partial \lambda}>0$, $\frac{\partial q_{2}^{M S *}}{\partial S}>0 ; \frac{\partial e^{M S *}}{\partial k}<0, \frac{\partial e^{M S *}}{\partial c}<0, \frac{\partial e^{M S *}}{\partial \theta}>0, \frac{\partial e^{M S *}}{\partial \lambda}>0, \frac{\partial e^{M S *}}{\partial s}>0$.

In the MS model, no matter how the operational environment changes, the regular product's wholesale and retail prices are constants. Similar to the $C$ model, the market demand for the regular product increases in green product R\&D cost coefficient, green product production cost, and decreases in consumers' green product function coefficient, consumers' green preference coefficient, and government subsidy. For the green product, the retail price, market demand, and green design level decrease in green product $R \& D$ cost coefficient, and increase in consumers' green product function coefficient, consumers' green preference coefficient, and government subsidy. The wholesale price of the green product decreases in green product R\&D cost coefficient but increases in consumers' green preference coefficient. The increase in green product production cost leads to the increases in the wholesale price and retail price of the green product, while it leads to the decreases in the market demand and green design level of the green product. 
Next, we turn to the government's problem in the MS model. Similarly, under the differentiated subsidy strategy, we consider the government's problem of maximizing entire social welfare. The government first decides the optimal subsidy for the green product. Then, it is followed by the supply chain's optimization problem. The government's decision-making problem in the MS model is formulated as

$$
\max _{s} S W^{M S}(s)=\pi_{s c}^{M S *}+C S^{M S *}-s q_{2}^{M S *}-t\left(q_{1}^{M S *}+(1-e) q_{2}^{M S *}\right)
$$

Substituting the optimal decisions given by Lemma 2 into Equation (12), we can obtain the optimal subsidy by solving the government's optimization problem.

Theorem 2. Under the differentiated subsidy strategy and MS model, the government's optimal subsidy that maximizes the total social welfare is

$$
s^{D M S *}=\frac{(\theta-1-c)(3 k(\theta-1)+\lambda(2 t+\lambda))}{k(\theta-1)-2 \lambda(t+\lambda)}
$$

From Theorem 2, we can derive the following Corollary 4.

Corollary 4. $\frac{\partial s^{D M S *}}{\partial k}<0, \frac{\partial S^{D M S *}}{\partial c}<0, \frac{\partial S^{D M S *}}{\partial \lambda}>0, \frac{\partial s^{D M S *}}{\partial t}>0$.

Like the $C$ model, when the government adopts a differentiated subsidy strategy, the increases in green product $R \& D$ cost coefficient and green product production cost lead to the decrease in government subsidy. The government subsidy increases in consumers green preference coefficient and negative environmental impact coefficient.

Substituting the optimal government subsidy given by Equation (13) into the equilibrium decision of the supply chain given by Lemma 3, we can derive Lemma 4 as follows.

Lemma 4. Under the differentiated subsidy strategy and MS model, the optimal wholesale prices, retail prices, and demands of the regular and green products, the optimal green product design level are $w_{1}^{D M S *}=\frac{1}{2}, w_{2}^{D M S *}=\frac{k(4 \theta-3-2 c)(\theta-1)-2(1+2 c) \lambda(t+\lambda)}{2 k(\theta-1)-4 \lambda(t+\lambda)}, p_{1}^{M S *}=\frac{3}{4}, p_{2}^{D M S *}=$ $\frac{k(12 \theta-9-8 c)(\theta-1)-2(3+4 c) \lambda(t+\lambda)}{4 k(\theta-1)-8 \lambda(t+\lambda)}, q_{1}^{D M S *}=\frac{1}{4}-\frac{k(\theta-1-c)}{k(\theta-1)-2 \lambda(t+\lambda)}, q_{2}^{D M S *}=\frac{k(\theta-1-c)}{k(\theta-1)-2 \lambda(t+\lambda)}$, $e^{D M S *}=\frac{(\theta-1-c) \lambda}{k(\theta-1)-2 \lambda(t+\lambda)}$.

\subsection{Retailer-Led Supply Chain (RS) Model}

In this subsection, we consider the scenario where the retailer has more channel power than the manufacturer. We call this scenario a retailer-led supply chain $(R S)$ model, in which the retailer acts as the Stackelberg game leader while the manufacturer acts as the follower. In the $R S$ model, the retailer decides the retail prices of the regular and green products. Then the manufacturer decides the green product design level and the wholesale prices of the regular and green products. The $R S$ model is formulated as

$$
\left\{\begin{array}{c}
\max _{p_{1}, p_{2}} \pi_{r}^{R S}\left(p_{1}, p_{2}\right)=\left(p_{1}-w_{1}^{*}\right) q_{1}+\left(p_{2}-w_{2}^{*}\right) q_{2} \\
w_{1}^{*}, w_{2}^{*} \text { and } e^{*} \text { are derived from solving the following problem, } \\
\max _{w_{1}, w_{2}, e} \pi_{m}^{R S}\left(w_{1}, w_{2}, e\right)=w_{1} q_{1}+\left(w_{2}-c\right) q_{2}-\frac{1}{2} k e^{2}
\end{array}\right.
$$

where $q_{1}$ and $q_{2}$ are given by Equations (2) and (3). Without loss of generality, let $m_{1}$ and $m_{2}$ denote profit margins of the regular and green products, respectively. Then, we have

$$
p_{i}=w_{i}+m_{i}, \quad\left(m_{i}>0, i=1,2\right) .
$$


Substituting Equation (14) into the $R S$ model, we solve the $R S$ model, and Lemma 5 can be obtained.

Lemma 5. In the RS model, the optimal wholesale prices, retail prices and demands of the regular and green products, and the optimal green product design level are $w_{1}^{R S *}=\frac{1}{4}$, $w_{2}^{R S *}=$ $\frac{2 k(\theta-1)(3 c+s+\theta)-(1+4 c) \lambda^{2}}{8 k(\theta-1)-4 \lambda^{2}}, p_{1}^{*}=\frac{3}{4}, p_{2}^{R S *}=\frac{2 k(\theta-1)(c+3(s+\theta))-\lambda^{2}-2(c+s+\theta) \lambda^{2}}{8 k(\theta-1)-4 \lambda^{2}}, q_{1}^{R S *}=\frac{2 k(c-s)-\lambda^{2}}{8 k(\theta-1)-4 \lambda^{2}}$, $q_{2}^{R S *}=\frac{k(s+\theta-1-c)}{4 k(\theta-1)-2 \lambda^{2}}, e^{R S *}=\frac{(s+\theta-1-c) \lambda}{4 k(\theta-1)-2 \lambda^{2}}$.

According to Lemma 5, the following Corollary 5 can be obtained.

Corollary 5. In the RS model,

(1) for the regular product: $\frac{\partial q_{1}^{R S *}}{\partial k}>0, \frac{\partial q_{1}^{R S *}}{\partial c}>0, \frac{\partial q_{1}^{R S *}}{\partial \theta}<0, \frac{\partial q_{1}^{R S *}}{\partial \lambda}<0, \frac{\partial q_{1}^{R S *}}{\partial s}<0$;

(2) for the green product: $\frac{\partial w_{2}^{R S *}}{\partial k}<0, \frac{\partial w_{2}^{R S *}}{\partial c}>0, \frac{\partial w_{2}^{R S *}}{\partial \lambda}>0, \frac{\partial w_{2}^{R S *}}{\partial s}>0 ; \frac{\partial p_{2}^{R S *}}{\partial k}<0, \frac{\partial p_{2}^{R S *}}{\partial c}>0$, $\frac{\partial p_{2}^{R S *}}{\partial \lambda}>0, \frac{\partial p_{2}^{R S *}}{\partial s}>0 ; \frac{\partial q_{2}^{R S *}}{\partial k}<0, \frac{\partial q_{2}^{R S *}}{\partial c}<0, \frac{\partial q_{2}^{R S *}}{\partial \theta}>0, \frac{\partial q_{2}^{R S *}}{\partial \lambda}>0, \frac{\partial q_{2}^{R S *}}{\partial s}>0 ; \frac{\partial e^{R S *}}{\partial k}<0$, $\frac{\partial e^{R S *}}{\partial c}<0, \frac{\partial e^{R S *}}{\partial \theta}>0, \frac{\partial e^{R S *}}{\partial \lambda}>0, \frac{\partial e^{R S *}}{\partial S}>0$.

Similar to the $C$ and $M S$ model, in the $R S$ model, the regular product's wholesale price and retail price have nothing to do with model parameters. The green product $R \& D$ cost coefficient hurts the wholesale price and retail price of the green product, while the green product production cost positively impacts the wholesale price and retail price of the green product. The green product $R \& D$ cost coefficient and green product production cost both harm the market demand and green design level of the green product, while they positively impact market demand for the regular product. The consumers' green preference and government subsidy both have a positive impact on the wholesale price, retail price, market demand, and green design level of the green product. In contrast, they have a negative impact on the retail price of regular product.

In the following, we turn to the government's problem in the $R S$ model. Under the differentiated subsidy strategy, we consider the government's problem of maximizing entire social welfare. The government first decides the optimal subsidy for the green product. Then, it is followed by the supply chain's optimization problem. The government's decision-making problem in the $R S$ model is formulated as

$$
\max _{s} S W^{R S}(s)=\pi_{s c}^{R S *}+C S^{R S *}-s q_{2}^{R S *}-t\left(q_{1}^{R S *}+(1-e) q_{2}^{R S *}\right)
$$

Substituting the optimal decisions given by Lemma 5 into Equation (15), we can obtain the optimal subsidy by solving the government's optimization problem.

Theorem 3. Under the differentiated subsidy strategy and RS model, the government's optimal subsidy that maximizes the total social welfare is

$$
s^{D R S *}=\frac{(\theta-1-c)(3 k(\theta-1)+2 t \lambda)}{k(\theta-1)-2 \lambda(t+\lambda)}
$$

From Theorem 3, we can derive the following Corollary 6.

Corollary 6. $\frac{\partial s^{D R S *}}{\partial k}<0, \frac{\partial s^{D R S *}}{\partial c}<0, \frac{\partial s^{D R S *}}{\partial \lambda}>0, \frac{\partial s^{D R S *}}{\partial t}>0$.

Like the $C$ and $M S$ model, the green product R\&D cost coefficient and production cost negatively impact the government subsidy. In contrast, the consumers' green preference and negative environmental impact coefficient have positive impacts. 
Substituting the optimal government subsidy given by Equation (16) into the equilibrium decision of the supply chain given by Lemma 5, we can derive Lemma 6 as follows.

Lemma 6. Under the differentiated subsidy strategy and RS model, the optimal wholesale prices, retail prices, and demands of the regular and green products, the optimal green product design level are $w_{1}^{D R S *}=\frac{1}{4}, w_{2}^{D R S *}=\frac{k(\theta-1)(4 \theta-3)-2(1+4 c) \lambda(t+\lambda)}{4 k(\theta-1)-8 \lambda(t+\lambda)}, p_{1}^{*}=\frac{3}{4}, p_{2}^{D R S *}=$ $\frac{k(12 \theta-9-8 c)(\theta-1)-2 \lambda((3+4 c) t+\lambda+2(c+\theta) \lambda)}{4 k(\theta-1)-8 \lambda(t+\lambda)}, q_{1}^{D R S *}=\frac{1}{4}-\frac{k(\theta-1-c)}{k(\theta-1)-2 \lambda(t+\lambda)}, q_{2}^{D R S *}=\frac{k(\theta-1-c)}{k(\theta-1)-2 \lambda(t+\lambda)}$, $e^{D R S *}=\frac{(\theta-1-c) \lambda}{k(\theta-1)-2 \lambda(t+\lambda)}$.

\section{Comparisons}

In this section, we compare the optimal decisions and profits of the supply chain and the optimal subsidy given by the government under different channel power structures (i.e., $C, M S$, and $R S$ models) and subsidy strategies of the government. We also investigate the impacts of key model parameters on the optimal decisions and profits (or social welfare) of the supply chain and government through a numerical analysis method.

\subsection{Uniform Subsidy Strategy of Government}

In this subsection, we consider the scenario where the government offers uniform subsidies to the consumers regardless of the supply chain structures. Under this scenario, we compare the optimal decisions in the $C, M S$, and $R S$ models and find some important managerial implications.

Proposition 1. $w_{1}^{M S *}=2 w_{1}^{R S *}, p_{1}^{M S *}=p_{1}^{R S *}>p_{1}^{C *} ; w_{2}^{M S *}>w_{2}^{R S *}, p_{2}^{M S *}>p_{2}^{R S *}>p_{2}^{C *}$.

The above Proposition compares the optimal wholesale prices and retailer prices of the regular and green products under three models. From Proposition 1, due to the manufacturer's first-mover advantage, the wholesale prices of the regular and green products in the $M S$ model are greater than those in the $R S$ model. The retail price of the green product in the $M S$ model is greater than the retail price in the $R S$ model, while the retail price of the regular product in the $M S$ model is equal to the retail price in the $R S$ model. Because of the double marginalization effect, the retail price of the regular and green products in $M S$ and $R S$ models are both greater than the retail price in the $C$ model.

Proposition 2. $q_{2}^{C *}>q_{2}^{R S *}>q_{2}^{M S *}$; If $\lambda^{2}<3 k(\theta-1)-k \sqrt{(\theta-1)(9(\theta-1)-8(c-s))}$, then $q_{1}^{C *}>q_{1}^{M S *}>q_{1}^{R S *} ;$ otherwise, $q_{1}^{M S *}>q_{1}^{C *}>q_{1}^{R S *} ; \frac{q_{2}^{C *}}{q_{1}^{C *}+q_{2}^{C *}}=\frac{q_{2}^{R S *}}{q_{1}^{R S *}+q_{2}^{R S *}}>\frac{q_{2}^{M S *}}{q_{1}^{M S *}+q_{2}^{M S *}}$.

Regarding the green product, the market demand for the green product in the $R S$ model is more significant than that in the $M S$ model, but both are less than the market demand in the $C$ model. It means that the retailer-led supply chain model can achieve broader market coverage of the green product. Regarding the regular product, unlike the above scenario, the demand for the regular product in the MS model is greater than that in the $R S$ model. It means that the manufacturing-led supply chain model can achieve broader market coverage of the regular product. In summary, compared with the MS model, the green product can achieve more extensive market coverage (i.e., $q_{2}^{R S *}>q_{2}^{M S *}$ ) and a higher market share in the $R S$ model (i.e., $\frac{q_{2}^{R S *}}{q_{1}^{R S *}+q_{2}^{R S *}}>\frac{q_{2}^{M S *}}{q_{1}^{M S *}+q_{2}^{M S *}}$ ). Moreover, the market share of the green product in the $R S$ model is the same as that in the $C$ model (i.e., $\frac{q_{2}^{C *}}{q_{1}^{C *}+q_{2}^{C *}}=\frac{q_{2}^{R S *}}{q_{1}^{R S *}+q_{2}^{R S *}}$ ). When consumers' green preference coefficient is relatively small, the market demand for the regular product in the MS model is less than that in the $C$ model. Otherwise, the market demand for the regular product in the MS model is more than that in the $C$ model. The underlying managerial implication is that establishing 
a retailer-led supply chain is more beneficial for the enterprise to expand the market share of green product.

Proposition 3. $e^{C *}>e^{R S *}>e^{M S *}, e^{R S *}=\frac{1}{2} e^{C *}$.

The green product design level in the RS model is greater than that in the MS model, but it is smaller than that in the $C$ model. From Propositions 1 and 2, compared with the $M S$ model, in the RS model, the green product can not only achieve a larger market coverage, but its retail price is also lower. Moreover, the green product is greener and more environmentally friendly in the $R S$ model. Therefore, from the perspective of the green design level, when the government provides a uniform subsidy strategy, it is a good choice for the enterprise to develop a retailer-led supply chain structure.

\subsection{Differentiated Subsidy Strategy of Government}

In this subsection, we consider the scenario where the government offers differentiated subsidies to the consumers based on different supply chain structures. We compare the optimal decisions in three models and investigate the impacts of government subsidy strategy on supply chain decisions. Some important managerial implications are also given.

Proposition 4. $w_{1}^{D M S *}=2 w_{1}^{D R S *}, p_{1}^{D M S *}=p_{1}^{D R S *}>p_{1}^{D C *} ; w_{2}^{D M S *}>w_{2}^{D R S *}$, $p_{2}^{D M S *}>p_{2}^{D R S *}$.

According to Propositions 1 and 4, when the government provides a differentiated subsidy strategy, the relationship between the wholesale price and retail price of the regular and green products in different supply chain models is the same as the scenario when the government provides a uniform subsidy strategy. For example, the wholesale and retail prices of the green product in the MS model are higher than those in the RS model under the differentiated subsidy strategy of the government. This shows that the government's differentiated subsidy strategy does not change the pricing relationships of the regular and green products in $C, M S$, and $R S$ models.

Proposition 5. $q_{1}^{D C *}>q_{1}^{D M S *}=q_{1}^{D R S *}, q_{2}^{D R S *}=q_{2}^{D M S *}>q_{2}^{D C *}, \frac{q_{2}^{D R S *}}{q_{1}^{D S S *}+q_{2}^{D R S *}}=\frac{q_{2}^{D M S *}}{q_{1}^{D M S *}+q_{2}^{D M S *}}$ $>\frac{q_{2}^{D C *}}{q_{1}^{D C *}+q_{2}^{D C *}}$.

Unlike the scenario where the government provides a uniform subsidy strategy when the government provides a differentiated subsidy strategy, the market demand of the regular (green) product in the MS model is the same as that of the regular (green) product in the RS model. That is to say, the differentiated subsidy strategy of the government can eliminate the impact of the different channel powers on the market demands for regular and green products. Combining Proposition 4, although the retail prices of the green product under different decentralized supply chain structures are different, the corresponding market demands are indeed the same. Compared with the uniform subsidy strategy of the government, when the government provides a differentiated subsidy strategy, MS and $R S$ supply chain structures are equivalent. The enterprise can achieve more market demand (i.e., $q_{2}^{D R S *}=q_{2}^{D M S *}>q_{2}^{D C *}$ ) and market share (i.e., $\frac{q_{2}^{D R S *}}{q_{1}^{D R S *}+q_{2}^{D R S *}}=\frac{q_{2}^{D M S *}}{q_{1}^{D M S *}+q_{2}^{D M S *}}>$ $\left.\frac{q_{2}^{D C *}}{q_{1}^{D C *}+q_{2}^{D C *}}\right)$ for the green product in the MS and RS supply chain structures than those in the $C$ supply chain structure. The underlying managerial implication is that when the government provides a differentiated subsidy strategy, establishing a decentralized supply chain structure can enable the enterprise to obtain more extensive market coverage and market share.

Proposition 6. $e^{D R S *}=e^{D M S *}>e^{D C *}$. 
When the government provides a differentiated subsidy strategy, the green product design level in the $R S$ model is the same as that in the MS model. Moreover, they are both greater than the green product design level in the $C$ model. Combining Proposition 3, the government's differentiated subsidy strategy can eliminate the influence of different supply chain structures on the green design level. From the perspective of product greenness degree, the decentralized supply chain structure is better than the centralized supply chain structure under the government's differentiated subsidy strategy. The underlying managerial implication is that when the government provides a differentiated subsidy strategy, a decentralized supply chain is more conducive to the development of the green product.

Proposition 7. $s^{D M S *}>s^{D R S *}>s^{D C *}$.

When the government provides a differentiated subsidy strategy, the government subsidy level in the $R S$ model is smaller than that in the $M S$ model. However, it is greater than the subsidy level under the $C$ model. That is to say, in order to maximize the total social welfare, the RS model can enable the government to provide less subsidy compared with the MS model. A higher subsidy from the government can make the MS supply chain structure realize the same green design level as the $R S$ supply chain structure.

\subsection{Numerical Analyses}

Due to the complexity, it is hard to compare the decision-makers' profits and total social welfare under different supply chain structures and subsidy strategies of the government. Therefore, in this subsection, we use the numerical analysis method to obtain more managerial implications. We assume that the model parameters satisfy: $c=0.3$, $\theta=1.45, s=0.2, k=3, t=0.1$. The model parameters are set based on the assumptions presented in Section 3 and industry practice. The relevant literature widely adopts this kind of simulation method (e.g., $[5,7,13,14,32])$. The authors also conduct numerical experiments with other combinations of model parameters, which show that the main conclusions and analytical results in this study are robust. Because consumers' environmental preference has an important influence on the design of the green product and supply chain structure, we investigate the impacts of consumers' environmental preference coefficient $\lambda$ when $\lambda$ is from 0.5 to 0.7 . The above model parameters combination satisfies the parameters constraints so that our models are solvable and our analysis is effective.

\subsubsection{Uniform Subsidy Strategy of the Government}

Under the scenario where the government provides a uniform subsidy strategy, Figures 1-3 intuitively demonstrate the impacts of consumers' green preference coefficient on supply chain pricing decisions and supply chain profits under different supply chain structures. As shown in Figure 1, the wholesale price of the green product in the $M S$ model is much greater than that in the $R S$ model. The retail price of the green product in the MS model is slightly higher than that in the $R S$ model, while they are both greater than the retail price in the $C$ model. In addition, with the increase in the consumers' green preference, the wholesale price and retail price of the green product both increase in $M S$ and $R S$ models, respectively.

Figure 2 shows the changes in the market demand for the regular and green products in the $C, M S$, and $R S$ models, respectively when the consumers' green preference coefficient varies. As the figure shows, the improvement of consumers' green preference can increase the market demand for the green product in any supply chain structure while reducing the market demand for the regular product in any supply chain structure. For the green product, the market demand in the $C$ model is the highest, followed by the $R S$ model and $M S$ model. For the regular product, the market demand for the regular product in the $M S$ model is always greater than that in the $R S$ model and maybe greater than the market demand in the $C$ model. From Figure 2, we can also derive that green product can 
achieve more extensive market coverage and a higher market share in the RS model than the MS model.

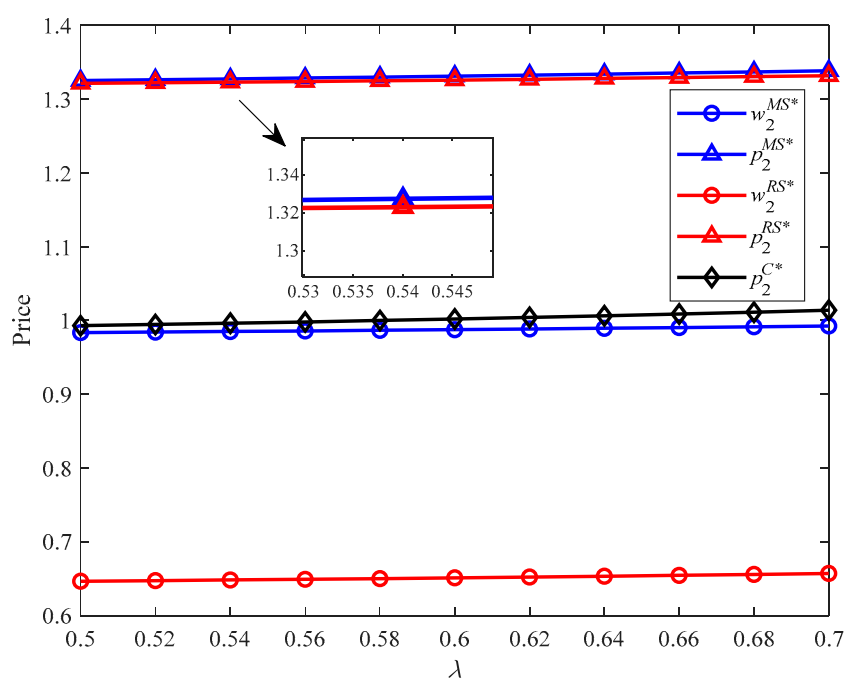

Figure 1. $w_{2}^{M S *}$ vs. $w_{2}^{R S *}, p_{2}^{M S *}$ vs. $p_{2}^{R S *}$.

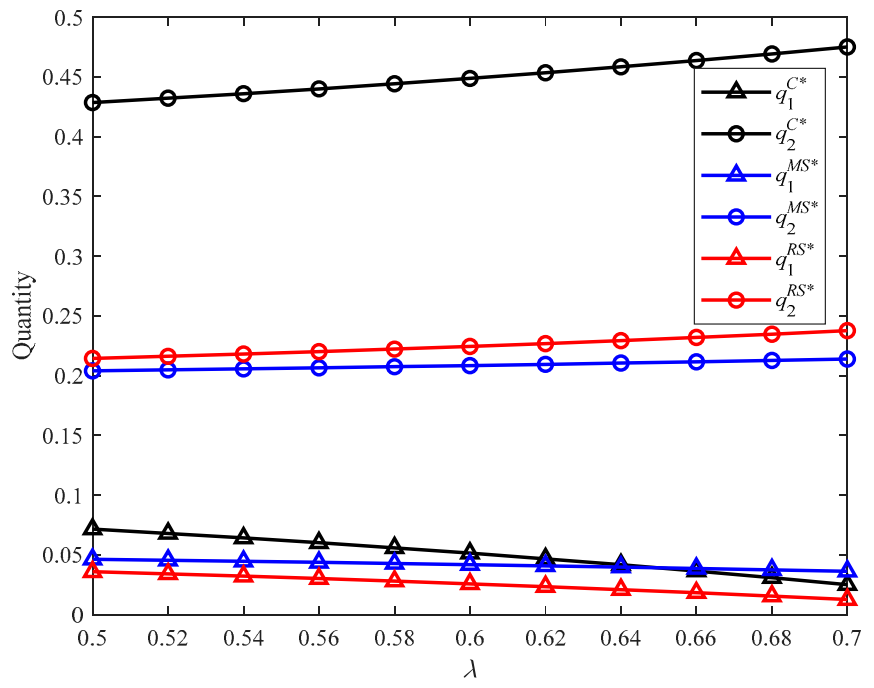

Figure 2. $q_{1}^{\mathrm{C} *}$ vs. $q_{1}^{M S *}$ vs. $q_{1}^{R S *}, q_{2}^{\mathrm{C} *}$ vs. $q_{2}^{M S *}$ vs. $q_{2}^{R S *}$.

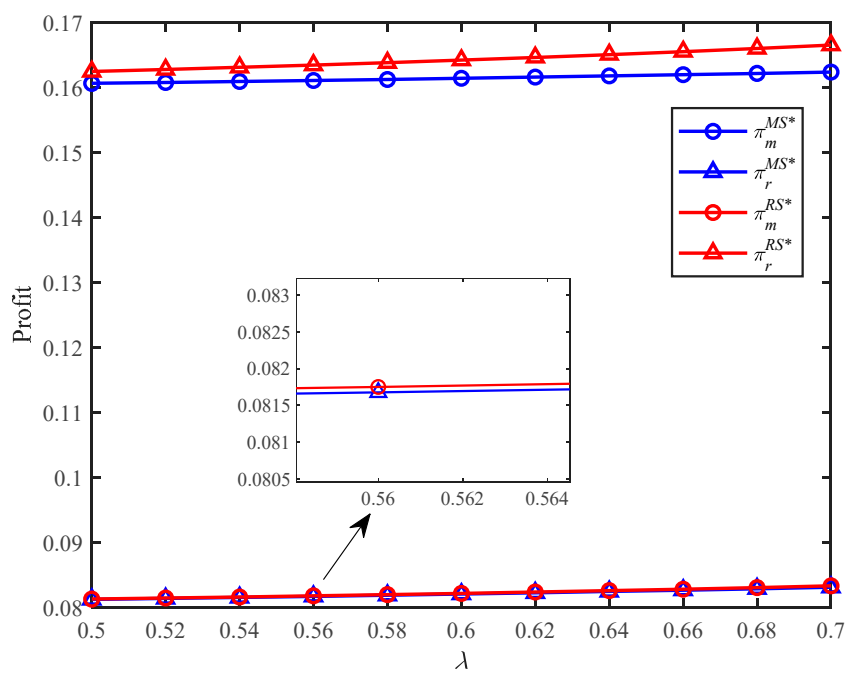

Figure 3. $\pi_{m}^{M S *}$ vs. $\pi_{m}^{R S *}, \pi_{r}^{M S *}$ vs. $\pi_{r}^{R S *}$. 
Figure 3 shows how the profits of the manufacturer and retailer in the MS and RS models vary with consumers' green preference coefficient. As the figure shows, the retailer's profit in the RS model is greater than the manufacturer's profit in the MS model. The manufacturer's profit in the RS model is slightly more significant than the retailer's in the MS model. This also shows that the total profit of the supply chain in the RS model is more significant than that in the MS model. With the increase in consumers' green preference, the profits of the manufacturer and retailer in the two models both increase.

Figures 4 and 5 show how the green product design level and total social welfare change with consumers' green preference coefficient under different supply chain structures. Figure 4 shows that the green design level in the $R S$ model is greater than that in the MS model but less than that in the $C$ model. With the increase in consumers' green preference, the green design level in any supply chain models increases. Figure 5 shows that the total social welfare in the RS model is slightly greater than that in the MS model but less than the total social welfare in the $C$ model. With the increase in consumers' green preference, the total social welfare in any supply chain models rises.

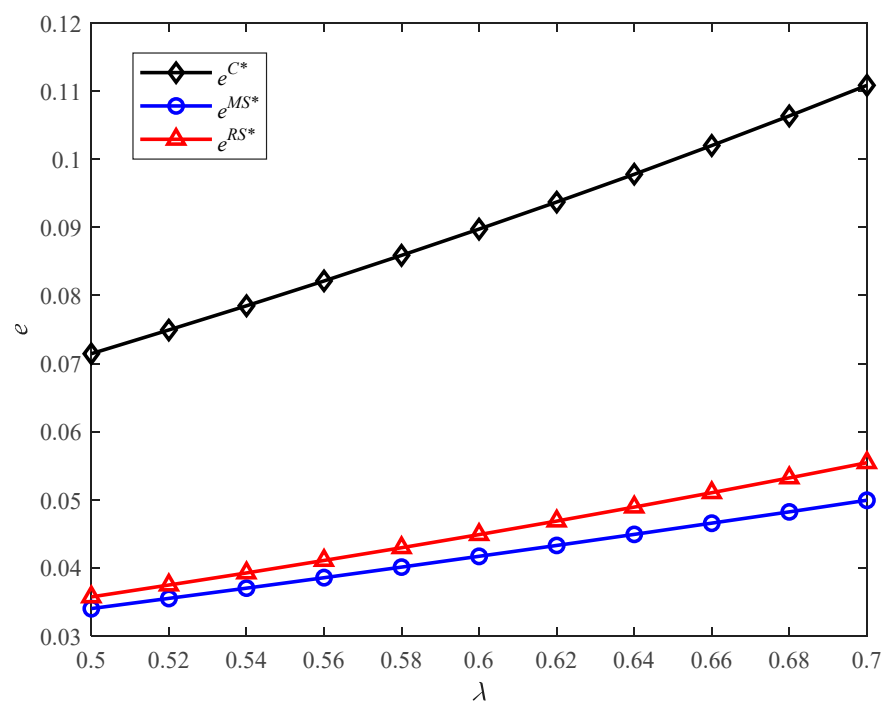

Figure 4. $e^{C *}$ vs. $e^{M S *}$ vs. $e^{R S *}$.

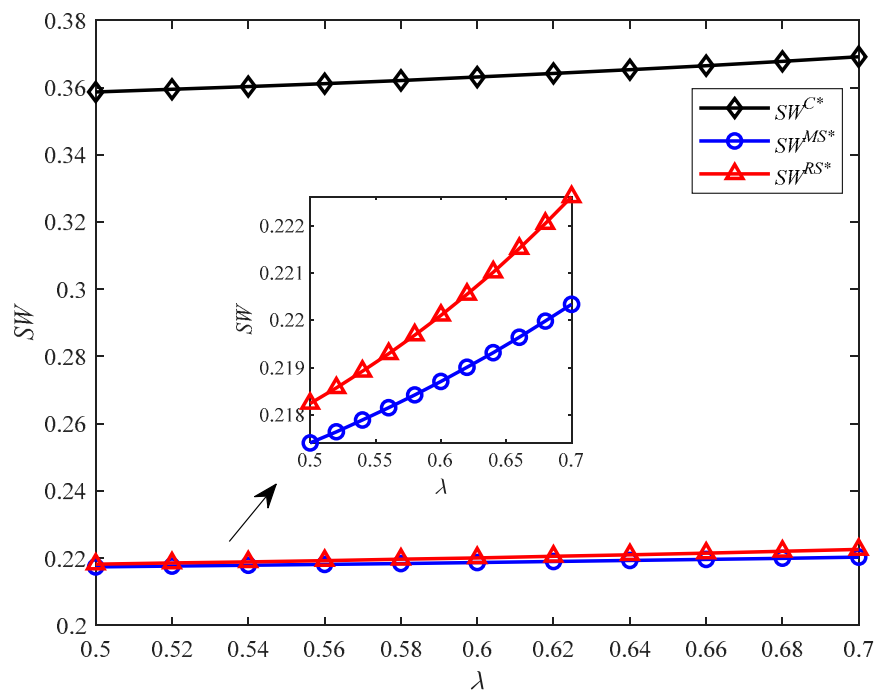

Figure 5. $S W^{C *}$ vs. $S W^{M S *}$ vs. $S W^{R S *}$. 


\subsubsection{Differentiated Subsidy Strategy of the Government}

Under the scenario where the government provides a differentiated subsidy strategy, Figures 6 and 7 visually demonstrate the impacts of consumers' green preference coefficient on supply chain pricing decisions and supply chain profits in different supply chain models. As Figure 6 shows, the wholesale price of the green product in the MS model is greater than that in the RS model. The retail price of the green product in the MS model is greater than that in the RS model. In addition, with the increase in consumers' green preference, the wholesale price and retail price of the green product in the two supply chain models both rise.

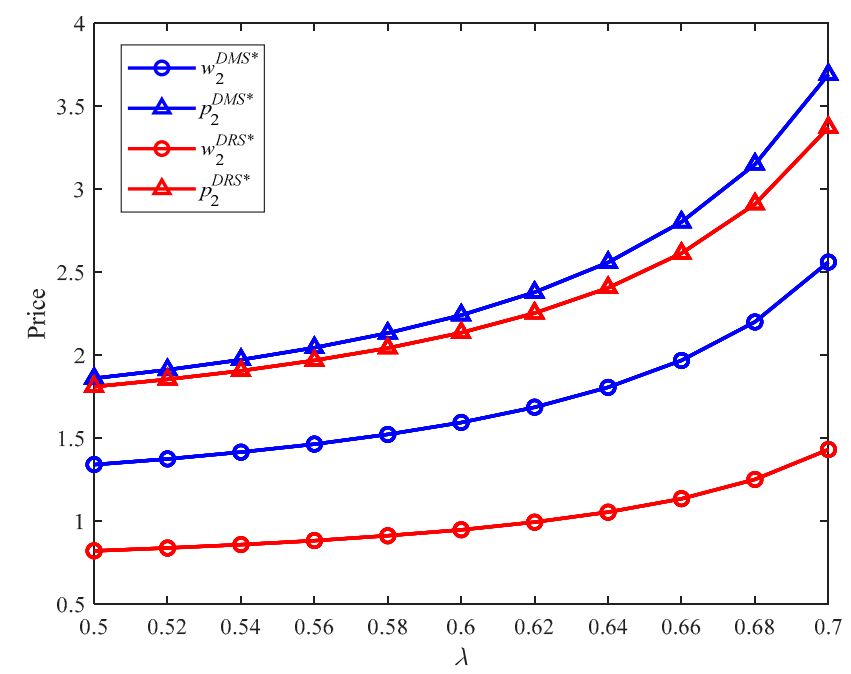

Figure 6. $w_{2}^{D M S *}$ vs. $w_{2}^{D R S *}, p_{2}^{D M S *}$ vs. $p_{2}^{D R S *}$.

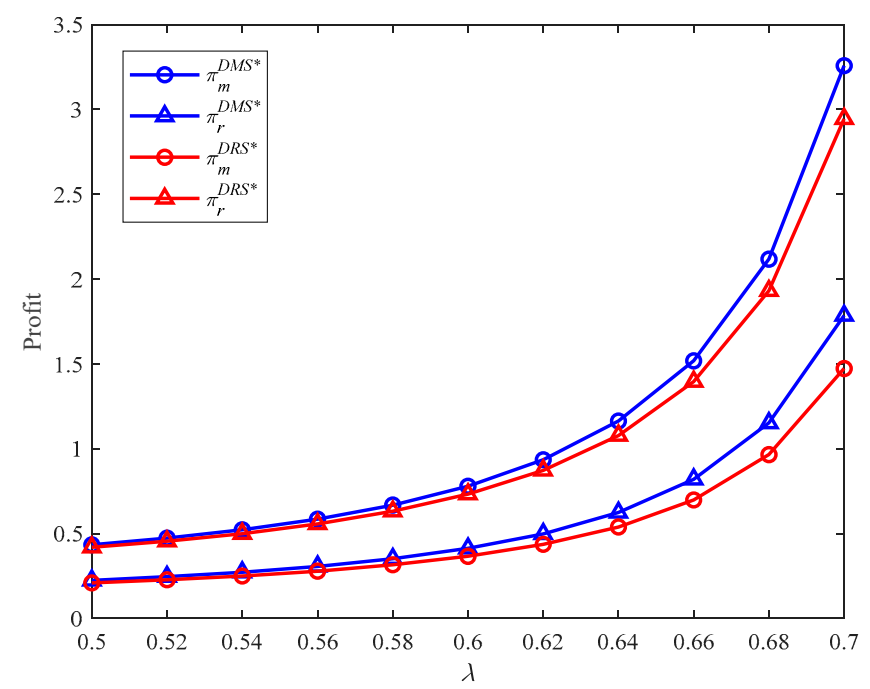

Figure 7. $\pi_{m}^{D M S *}$ vs. $\pi_{m}^{D R S *}, \pi_{r}^{D M S *}$ vs. $\pi_{r}^{D R S *}$.

Figure 7 shows how the profits of the manufacturer and retailer in the MS and RS models vary with consumers' green preference coefficient. Contrary to the government's uniform subsidy strategy, the manufacturer's profit in the MS model is greater than the retailer's profit in the RS model. The retailer's profit in the $M S$ model is also slightly greater than the manufacturer's profit in the RS model. This also shows, when the government offers a differential pricing strategy, the total profit of the supply chain in the MS model is greater than that in the RS model. With the increase in consumers' green preference, the profits of the manufacturer and retailer in the MS and RS models both increase.

Figure 8 shows how the green product design level varies with consumers' green preference coefficient in different supply chain models. The green design level in the $R S$ 
model is equal to the green design level in the MS model, which is greater than that in the $C$ model and is also greater than those in both $M S$ and $R S$ models under the scenario where the government provides a uniform subsidy strategy (compared with Figure 4). That is to say, the government's differentiated subsidy strategy can improve the green product design level, and it can also eliminate the impacts of different supply chain structures on the green design level.

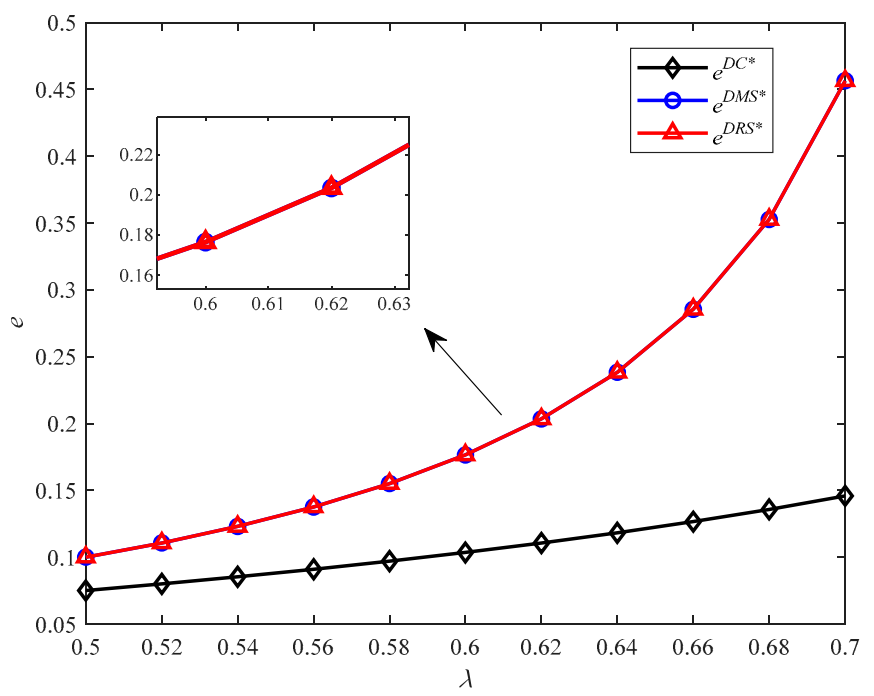

Figure 8. $e^{D C *}$ vs. $e^{D M S *}$ vs. $e^{D R S *}$.

Figures 9 and 10 show how the government's optimal subsidy and total social welfare change with consumers' green preference coefficient under different supply chain structures. As Figure 9 shows, the government's optimal subsidy in the $R S$ model is less than that in the MS model. However, it is greater than that in the $C$ model. As Figure 10 shows, the total social welfare in the RS model is equal to the total social welfare in the MS model, but it is less than that in the $C$ model. In conclusion, the government needs to provide higher subsidy in the $M S$ model to achieve the same total social welfare compared with the $R S$ model. The government's differentiated subsidy strategy can eliminate the impacts of different supply chain structures on total social welfare.

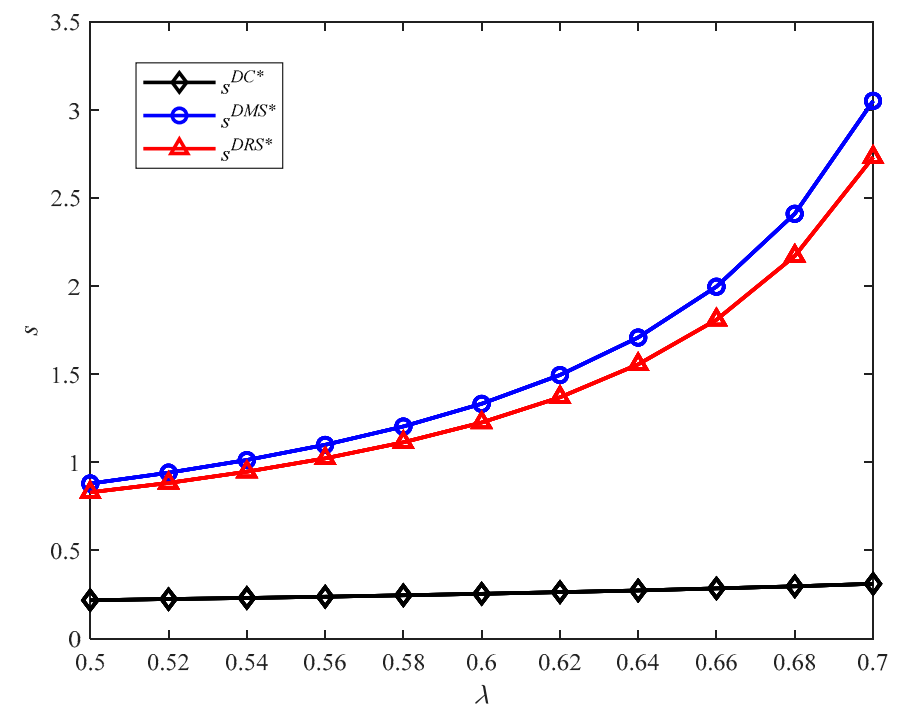

Figure 9. $s^{D C *}$ vs. $s^{D M S *}$ vs. $s^{D R S *}$. 


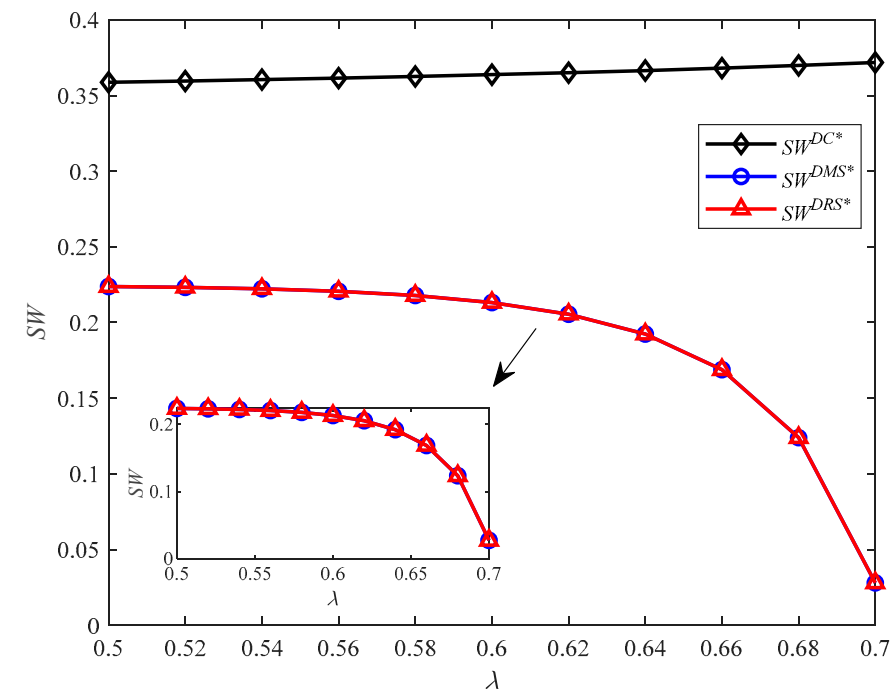

Figure 10. $S W^{D C *}$ vs. $S W^{D M S *}$ vs. $S W^{D R S *}$.

Different from the uniform subsidy strategy of the government, with the increase in consumers' green preference, the total social welfare in the $M S$ and $R S$ models decreases. This is because the government needs to provide more subsidies to consumers in the $M S$ and RS models, reducing the total social welfare. In other words, as consumers' green preference increases, the expenditure of government subsidy exceeds the increase in consumer utility and supply chain profit and the improvement of the environment. Therefore, the total social welfare declines in consumers' green preference.

\section{Conclusions}

To promote sustainable development in a circular economy era, this paper studies the multi-product pricing and green product design strategies in a sustainable supply chain consisting of a manufacturer and a retailer, considering the coexistence of the regular and green products under different supply chain structures. We also investigate the impacts of different government subsidy strategies, i.e., uniform subsidy strategy and differentiated subsidy strategy, on supply chain decisions and social welfare. By the utility model, the consumer demand function is constructed. Then, considering different channel powers, we establish the $C, M S$, and RS models, respectively. By solving the three models, the optimal decisions of the supply chain and the government are obtained. In addition, under both uniform subsidy strategy and differentiated subsidy strategy, we compare the wholesale prices, retail prices, market demands, green product design level, and the government's optimal subsidies in different models. Finally, using the numerical analysis method, we discuss the impacts of the ever-changing operational environment on supply chain decisions, profits, and total social welfare. Based on our research, we derive the following theoretical results and managerial implications.

\subsection{Theoretical Results}

The main theoretical results are as follows:

1. The consumers' green preference has a positive impact on the design and development of the green product and supply chain profits under different supply chain structures. However, the R\&D and production costs hurt the market demand and green design level for green product. Thus, it makes the firm reluctant to invest in green product development. Our findings extend the results from Hong et al. [16]. They only explored the impacts of CEA and green production cost on the pricing strategies without considering endogenous green product design.

2. When the government provides a uniform pricing strategy in the $R S$ structure, the green product design level, total supply chain profit, and total social welfare are all 
more significant than those in the MS structure. Compared with the MS structure, the green product can achieve more extensive market coverage and a higher market share in the RS structure. In other words, the retailer-led supply chain structure is superior to the manufacturer-led supply chain structure. Hong et al. [6] also find the environmental performance improvements of the $R S$ structure. However, we also find that the advantage of the $R S$ structure will change if the government provides a differentiated subsidy strategy.

3. When the government provides a differentiated subsidy strategy, MS and RS supply chain structures can bring greener products and more market demands than the centralized supply chain. From the firm's perspective, given the differentiated subsidy strategy of the government, establishing a decentralized supply chain structure can enable the enterprise to obtain more extensive market coverage and market share. From the perspective of social welfare, $M S$ and $R S$ supply chain structures are equivalent for the firm. These findings extend the relevant studies, e.g., Agi and Yan [5], Bian et al. [7], Zhu and He [23], etc.

4. For the government, compared with providing a uniform pricing strategy, providing a differentiated subsidy strategy can alter the product market structure and the development strategy of the green product. That is to say, the government's differentiated subsidy strategy can make the firm achieve a larger market share for the green product and a more environmentally friendly and greener product. In addition, the government's differentiated subsidy strategy can eliminate the influence of the supply chain structure on the green product design, market demand, and total social welfare.

\subsection{Managerial Implications}

The results based on theoretical analyses provide managerial implications to guide enterprise and government to make more reasonable operational decisions in the circular economy era.

From the perspective of the enterprise, it is recommended that the enterprise invest more in $R \& D$ technology and talent to boost the green technology R\&D efficiency and decrease the cost of green products. Because of the improvement of green technology, R\&D efficiency positively impacts the price and market demand of green products. This insight supplements the relevant studies about green design (Sim et al. [13], Ghosh and Shah [19], Shen et al. [37]). At the supply chain level, it is a better choice for the enterprise to establish a retailer-led supply chain structure under the uniform subsidy strategy. Establishing a retailer-led supply chain is more beneficial for the enterprise to expand the market share of green product on the one hand. On the other hand, green product is greener and more environmentally friendly in the retailer-led supply chain. This is different from the findings of Agi and Yan [5]. Without considering government subsidy, they find that the manufacturer-led supply chain is better prepared to launch the green product than the retailer-led one. Our findings also complement the conclusions of Hong et al. [6]. For examole, if under the differentiated subsidy strategy, a decentralized supply chain can enable the enterprise to obtain more extensive market coverage and market share of green product.

From the perspective of the government, in the early stage of green product development, it is suggested that the government adopt a differentiated subsidy strategy to promote the development of the green product market. With the development of the green industry, the government could turn to the uniform subsidy strategy. In the study of Bian et al. [7], they explore the manufacturer subsidy and consumer subsidy. Furthermore, we find that the government can use different types of consumer subsidies to promote green industry development. Consumers are willing to pay higher prices for their green preferences. The increase in consumers' green awareness is conducive to the development of the green product market. This finding supports the studies of Li and Li [9] and Zhang et al. [15]. In order to realize the sustainable development of our society, it is beneficial to adopt various reasonable measures to boost consumers' environmental awareness. 


\subsection{Future Research}

Our research provides important managerial insights and decision-making reference for the firm to establish an appropriate supply chain structure and implement green product development strategy to promote sustainable development. However, some limitations leave room for future research. For example, we consider two different consumer subsidies from the government. In reality, the government could also provide subsidy to the manufacturer directly to promote sustainable production. In the future, we will consider the impacts of the manufacturer subsidy from the government on green product design under different channel structures. Furthermore, in the platform economy era, the firm usually has multiple sales channels and faces retail competition. Thus, it will also be interesting to explore the effects of retail competition on green product design in the future.

Author Contributions: Conceptualization, K.X., G.S. and Y.W.; methodology, K.X. and G.S.; software, K.X. and G.S.; supervision, Y.W. and S.N.; writing-original draft, K.X. and G.S.; writing-review and editing, Y.W. and S.N.; project administration, Y.W. and S.N.; funding acquisition, G.S., Y.W. and S.N. All authors have read and agreed to the published version of the manuscript.

Funding: This research was funded by (i) the Humanities and Social Sciences Research Project of Ministry of Education of China, grant number 20YJC630178; (ii) the Social Science Planning and Research Project of Shandong Province, China, grant number 20DGLJ09; (iii) the National Natural Science Foundation of China, grant number 71802143, 72002114; (iv) Fundamental Research Funds of Shandong University, grant number 2020GN044.

Institutional Review Board Statement: Not applicable.

Informed Consent Statement: Not applicable.

Data Availability Statement: Not applicable.

Conflicts of Interest: The authors declare no conflict of interest.

\section{Appendix A}

\section{Proof of Lemma 1.}

Firstly, we verify whether $\pi_{s c}^{C}\left(p_{1}, p_{2}, e\right)$ exists the optimal solutions. We have

$$
\begin{gathered}
\frac{\partial^{2} \pi_{s c}\left(p_{1}, p_{2}, e\right)}{\partial\left(p_{1}\right)^{2}}=-\frac{2 \theta}{\theta-1}<0, \\
\left|\begin{array}{ll}
\frac{\partial^{2} \pi_{s c}\left(p_{1}, p_{2}, e\right)}{\partial\left(p_{1}\right)^{2}} & \frac{\partial^{2} \pi_{s c}\left(p_{1}, p_{2}, e\right)}{\partial p_{1} \partial p_{2}} \\
\frac{\partial^{2} \pi_{s c}\left(p_{1}, p_{2}, e\right)}{\partial p_{1} \partial p_{2}} & \frac{\partial^{2} \pi_{s c}\left(p_{1}, p_{2}, e\right)}{\partial\left(p_{2}\right)^{2}}
\end{array}\right|=\frac{4}{\theta-1}>0, \\
H\left(\pi_{s c}\right)=\left|\begin{array}{lll}
\frac{\partial^{2} \pi_{s c}\left(p_{1}, p_{2}, e\right)}{\partial\left(p_{1}\right)^{2}} & \frac{\partial^{2} \pi_{s c}\left(p_{1}, p_{2}, e\right)}{\partial p_{1} \partial p_{2}} & \frac{\partial^{2} \pi_{s c}\left(p_{1}, p_{2}, e\right)}{\partial p_{1} \partial e} \\
\frac{\partial^{2} \pi_{s c}\left(p_{1}, p_{2}, e\right)}{\partial p_{2} \partial p_{1}} & \frac{\partial^{2} \pi_{s c}\left(p_{1}, p_{2}, e\right)}{\partial\left(p_{2}\right)^{2}} & \frac{\partial^{2} \pi_{s c}\left(p_{1}, p_{2}, e\right)}{\partial p_{2} \partial e} \\
\frac{\partial^{2} \pi_{s c}\left(p_{1}, p_{2}, e\right)}{\partial e \partial p_{1}} & \frac{\partial^{2} \pi_{s c}\left(p_{1}, p_{2}, e\right)}{\partial e \partial p_{2}} & \frac{\partial^{2} \pi_{s c}\left(p_{1}, p_{2}, e\right)}{\partial(e)^{2}}
\end{array}\right| \\
=\frac{-4 k(\theta-1)+2 \lambda^{2}}{(\theta-1)^{2}}
\end{gathered}
$$

Because of $k(\theta-1)>2 \lambda(2 t+\lambda)$, then $4 k(\theta-1)>2 \lambda^{2}$ and $H\left(\pi_{s c}\right)<0$. Hence, $H\left(\pi_{s c}\right)$ is negative definite. The objective function $\pi_{s c}\left(p_{1}, p_{2}, e\right)$ is jointly concave in $p_{1}$, $p_{2}$ and $e$. By the first-order conditions (FOC), let the first derivatives of $\pi_{s c}\left(p_{1}, p_{2}, e\right)$ with respect to (w.r.t.) $p_{1}, p_{2}$ and $e$ equal to zero. We derive the optimal solutions satisfying

$$
\left\{\begin{array}{c}
p_{1}^{C *}=\frac{1}{2} \\
p_{2}^{C *}=\frac{2 k(\theta-1)(c+s+\theta)-(1+2 c) \lambda^{2}}{4 k(\theta-1)-2 \lambda^{2}} \\
e^{C *}=\frac{(s+\theta-c-1) \lambda}{2 k(\theta-1)-\lambda^{2}}
\end{array} .\right.
$$


Therefore, in the $C$ model, the optimal demands $q_{1}^{C *}$ and $q_{2}^{C *}$ of the regular and green products are $q_{1}^{\mathrm{C} *}=\frac{2 k(c-s)-\lambda^{2}}{4 k(\theta-1)-2 \lambda^{2}}, q_{2}^{\mathrm{C} *}=\frac{k(s+\theta-c-1)}{2 k(\theta-1)-\lambda^{2}}$.

Then, Lemma 1 is proven.

Proof of Corollary 1. Based on the assumption conditions of $2 k(c-s)>\lambda^{2}, \theta-1>c$ and $k(\theta-1)>2 \lambda(2 t+\lambda)$, it is easy to derive that $s+\theta-1-c>0$ and $k(\theta-1)>\lambda^{2}$. Therefore, (1) $\frac{\partial q_{1}^{C *}}{\partial k}=\frac{(s+\theta-1-c) \lambda^{2}}{\left(2 k(\theta-1)-\lambda^{2}\right)^{2}}>0, \frac{\partial q_{1}^{C *}}{\partial c}=\frac{2 k}{4 k(\theta-1)-2 \lambda^{2}}>0, \frac{\partial q_{1}^{C *}}{\partial \theta}=-\frac{k\left(2 k(c-s)-\lambda^{2}\right)}{\left(2 k(\theta-1)-\lambda^{2}\right)^{2}}<0$, $\frac{\partial q_{1}^{C *}}{\partial \lambda}=-\frac{2 k(s+\theta-1-c) \lambda}{\left(2 k(\theta-1)-\lambda^{2}\right)^{2}}<0, \frac{\partial q_{1}^{C_{*}}}{\partial s}=-\frac{k}{2 k(\theta-1)-\lambda^{2}}<0$; (2) $\frac{\partial p_{2}^{C *}}{\partial k}=-\frac{(\theta-1)(s+\theta-1-c) \lambda^{2}}{\left(2 k(\theta-1)-\lambda^{2}\right)^{2}}<0$, $\frac{\partial p_{2}^{C *}}{\partial c}=\frac{2 k(\theta-1)-2 \lambda^{2}}{4 k(\theta-1)-2 \lambda^{2}}>0, \frac{\partial p_{2}^{\mathcal{C}}}{\partial \theta}=\frac{k\left(2 k(\theta-1)^{2}+(2+c-s-2 \theta) \lambda^{2}\right)}{\left(2 k(\theta-1)-\lambda^{2}\right)^{2}}>0, \frac{\partial p_{2}^{\complement *}}{\partial \lambda}=\frac{2 k(s+\theta-1-c)(\theta-1) \lambda}{\left(2 k(\theta-1)-\lambda^{2}\right)^{2}}>0$, $\frac{\partial p_{2}^{\mathcal{C} *}}{\partial s}=\frac{k(\theta-1)}{2 k(\theta-1)-\lambda^{2}}>0 ; \frac{\partial q_{2}^{\mathcal{C} *}}{\partial k}=-\frac{(s+\theta-1-c) \lambda^{2}}{\left(2 k(\theta-1)-\lambda^{2}\right)^{2}}<0, \frac{\partial q_{2}^{\complement *}}{\partial c}=-\frac{k}{2 k(\theta-1)-\lambda^{2}}<0$, $\frac{\partial q_{2}^{\mathcal{C} *}}{\partial \theta}=\frac{k\left(2 k(c-s)-\lambda^{2}\right)}{\left(2 k(\theta-1)-\lambda^{2}\right)^{2}}>0, \frac{\partial q_{2}^{\mathcal{C} *}}{\partial \lambda}=\frac{2 k(s+\theta-1-c) \lambda}{\left(2 k(\theta-1)-\lambda^{2}\right)^{2}}>0, \frac{\partial q_{2}^{\mathcal{C} *}}{\partial s}=\frac{k}{2 k(\theta-1)-\lambda^{2}}>0 ;$ $\frac{\partial \mathcal{C}^{\mathcal{*}}}{\partial k}=-\frac{2(s+\theta-1-c)(\theta-1) \lambda}{\left(2 k(\theta-1)-\lambda^{2}\right)^{2}}<0, \frac{\partial \mathcal{C}^{*}}{\partial c}=-\frac{\lambda}{2 k(\theta-1)-\lambda^{2}}<0, \frac{\partial \mathcal{C}^{\mathcal{C} *}}{\partial \theta}=\frac{\lambda\left(2 k(c-s)-\lambda^{2}\right)}{\left(2 k(\theta-1)-\lambda^{2}\right)^{2}}>0$, $\frac{\partial \mathcal{C}^{*}}{\partial \lambda}=\frac{(s+\theta-1-c)\left(2 k(\theta-1)+\lambda^{2}\right)}{\left(2 k(\theta-1)-\lambda^{2}\right)^{2}}>0, \frac{\partial C^{\mathcal{C}}}{\partial s}=\frac{\lambda}{2 k(\theta-1)-\lambda^{2}}>0$.

Then, the Corollary 1 is proven.

\section{Proof of Theorem 1.}

Substituting the optimal decisions given by Lemma 1 into the government's objective function given by Equation (10), we have

$$
\begin{gathered}
S W^{C}(s)=\frac{1}{8\left(2 k(\theta-1)-\lambda^{2}\right)^{2}}\left(4 k ^ { 2 } ( \theta - 1 ) \left(3 c^{2}-s^{2}+2 s(\theta-1)\right.\right. \\
-(4 t-3 \theta)(\theta-1)-2 c(s+3 \theta-3)) \\
+8 k t(s+\theta-c-1)^{2} \lambda \\
-4 k\left(-2+c(2+c)-s^{2}+4 t+\theta-2(c+2 t) \theta+\theta^{2}\right) \lambda^{2} \\
\left.+(3-4 t) \lambda^{4}\right)
\end{gathered}
$$

Taking the second-order derivative of $S W^{C}(s)$ w.r.t. $s$, we have

$$
\frac{d S W^{C}(s)}{d s}=\frac{k(\lambda(2 t+\lambda)-k(\theta-1))}{\left(2 k(\theta-1)-\lambda^{2}\right)^{2}} .
$$

Because of $k(\theta-1)>2 \lambda(2 t+\lambda)$, then $k(\theta-1)>\lambda(2 t+\lambda)$, and $\frac{d S W^{C}(s)}{d s}<0$. Hence, $S W^{C}(s)$ has the optimal solution. By the FOC, the optimal subsidy of government is

$$
s^{C *}=\frac{(\theta-1-c)(k(\theta-1)+2 t \lambda)}{k(\theta-1)-\lambda(2 t+\lambda)} .
$$

Then, Theorem 1 is proven.

\section{Proof of Corollary 2.}

Similar to the proof of Corollary 1; it is omitted here because of its simplicity.

\section{Proof of Theorem 2.}

Substituting the optimal subsidy of government given by Theorem 1 into the equilibrium decisions of the supply chain given by Lemma 1, Theorem 2 can be derived. 


\section{Proof of Lemma 2:}

Firstly, we solve the retailer's optimization problem. We verify whether $\pi_{r}^{M S}\left(p_{1}, p_{2}\right)$ exists the optimal solutions. Because of

$$
\begin{aligned}
& \frac{\partial^{2} \pi_{r}^{M S}\left(p_{1}, p_{2}\right)}{\partial\left(p_{1}\right)^{2}}=-\frac{2 \theta}{\theta-1}<0, \\
& \left|\begin{array}{ll}
\frac{\partial^{2} \pi_{r}^{M S}\left(p_{1}, p_{2}\right)}{\partial\left(p_{1}\right)^{2}} & \frac{\partial^{2} \pi_{r}^{M S}\left(p_{1}, p_{2}\right)}{\partial p_{1} \partial p_{2}} \\
\frac{\partial^{2} \pi_{r}^{M S}\left(p_{1}, p_{2}\right)}{\partial p_{1} \partial p_{2}} & \frac{\partial^{2} \pi_{r}^{M S}\left(p_{1}, p_{2}\right)}{\partial\left(p_{2}\right)^{2}}
\end{array}\right|=\frac{4}{\theta-1}>0,
\end{aligned}
$$

hence $H\left(\pi_{r}^{M S}\right)$ is negative definite. $\pi_{r}^{M S}\left(p_{1}, p_{2}\right)$ is jointly concave in $p_{1}$ and $p_{2}$. By the FOC, the optimal pricing decisions of retailer are

$$
\left\{\begin{array}{c}
p_{1}^{M S *}=\frac{1+w_{1}}{2} \\
p_{2}^{M S *}=\frac{s+\theta+\lambda e+w_{2}}{2}
\end{array} .\right.
$$

Secondly, we solve the manufacturer's optimization problem. We verify whether $\pi_{m}^{M S}\left(w_{1}, w_{2}, e\right)$ exists the optimal solutions. We have

$$
\begin{gathered}
\frac{\partial^{2} \pi_{m}^{M S}\left(w_{1}, w_{2}, e\right)}{\partial\left(w_{1}\right)^{2}}=-\frac{\theta}{\theta-1}<0, \\
\left|\begin{array}{ll}
\frac{\partial^{2} \pi_{m}^{M S}\left(w_{1}, w_{2}, e\right)}{\partial\left(w_{1}\right)^{2}} & \frac{\partial^{2} \pi_{m}^{M S}\left(w_{1}, w_{2}, e\right)}{\partial w_{1} \partial w_{2}} \\
\frac{\partial^{2} \pi_{m}^{M S}\left(w_{1}, w_{2}, e\right)}{\partial w_{1} \partial w_{2}} & \frac{\partial^{2} \pi_{m}^{M S}\left(w_{1}, w_{2}, e\right)}{\partial\left(w_{2}\right)^{2}}
\end{array}\right|=\frac{1}{\theta-1}>0, \\
H\left(\pi_{m}\right)=\left|\begin{array}{lll}
\frac{\partial^{2} \pi_{m}^{M S}\left(w_{1}, w_{2}, e\right)}{\partial\left(w_{1}\right)^{2}} & \frac{\partial^{2} \pi_{m}^{M S}\left(w_{1}, w_{2}, e\right)}{\partial w_{1} \partial w_{2}} & \frac{\partial^{2} \pi_{m}^{M S}\left(w_{1}, w_{2}, e\right)}{\partial w_{1} \partial e} \\
\frac{\partial^{2} \pi_{m}^{M S}\left(w_{1}, w_{2}, e\right)}{\partial w_{2} \partial w_{1}} & \frac{\partial^{2} \pi_{m}^{M S}\left(w_{1}, w_{2}, e\right)}{\partial\left(w_{2}\right)^{2}} & \frac{\partial^{2} \pi_{m}^{M S}\left(w_{1}, w_{2}, e\right)}{\partial w_{2} \partial e} \\
\frac{\partial^{2} \pi_{m}^{M S}\left(w_{1}, w_{2}, e\right)}{\partial e \partial w_{1}} & \frac{\partial^{2} \pi_{m}^{M S}\left(w_{1}, w_{2}, e\right)}{\partial e \partial w_{2}} & \frac{\partial^{2} \pi_{m}^{M S}\left(w_{1}, w_{2}, e\right)}{\partial(e)^{2}}
\end{array}\right|=\frac{-4 k(\theta-1)+\lambda^{2}}{4(\theta-1)^{2}} .
\end{gathered}
$$

Because of $2 k(c-s)>\lambda^{2}$ and $\theta-1>c-s$, then $4 k(\theta-1)>\lambda^{2}$ and $H\left(\pi_{m}^{M S}\right)<0$. Hence, $H\left(\pi_{m}^{M S}\right)$ is negative definite. $\pi_{m}^{M S}\left(w_{1}, w_{2}, e\right)$ is jointly concave in $w_{1}, w_{2}$ and $e$. By the FOC, the optimal decisions of the manufacturer are

$$
\left\{\begin{array}{c}
w_{1}^{M S *}=\frac{1}{2} \\
w_{2}^{M S *}=\frac{4 k(\theta-1)(c+s+\theta)-(1+2 c) \lambda^{2}}{8 k(\theta-1)-2 \lambda^{2}} \\
e^{M S *}=\frac{(s+\theta-1-c) \lambda}{4 k(1-\theta)-\lambda^{2}} .
\end{array} .\right.
$$

Substituting the above optimal decisions into the optimal prices of the retailer, we can derive the equilibrium decisions of the supply chain as follows: $w_{1}^{M S *}=\frac{1}{2}, w_{2}^{M S *}=$ $\frac{4 k(\theta-1)(c+s+\theta)-(1+2 c) \lambda^{2}}{8 k(\theta-1)-2 \lambda^{2}}, e^{M S *}=\frac{(s+\theta-1-c) \lambda}{4 k(1-\theta)-\lambda^{2}}, q_{1}^{M S *}=\frac{4 k(c-s)-\lambda^{2}}{4\left(4 k(\theta-1)-\lambda^{2}\right)}, q_{2}^{M S *}=\frac{k(s+\theta-1-c)}{4 k(\theta-1)-\lambda^{2}}$, $p_{1}^{M S *}=\frac{3}{4}, p_{2}^{M S *}=\frac{4 k(\theta-1)(c+3(s+\theta))-(3+4 c) \lambda^{2}}{16 k(\theta-1)-4 \lambda^{2}}$.

Then, the Lemma 2 is proven.

Similar to the previous proof, the proof of Lemma 3, Theorems 3-6, and Corollaries 2-6 are omitted.

\section{Proof of Proposition 1.}

Based on the assumption conditions of $2 k(c-s)>\lambda^{2}, \theta-1>c$ and $k(\theta-1)>$ $2 \lambda(2 t+\lambda)$, we can derive $s+\theta-1-c>0$ and $k(\theta-1)>\lambda^{2}$. Therefore, $w_{2}^{\mathrm{MS} *}-w_{2}^{\mathrm{RS} *}=$ 


$$
\begin{aligned}
& \frac{2 k(s+\theta-c)(\theta-1)\left(4 k(\theta-1)-3 \lambda^{2}\right)+\lambda^{4}}{4\left(4 k(\theta-1)-\lambda^{2}\right)\left(2 k(\theta-1)-\lambda^{2}\right)}>0, p_{2}^{\mathrm{MS} *}-p_{2}^{\mathrm{RS} *}=\frac{(s+\theta-1-c) \lambda^{2}\left(k(\theta-1)-\lambda^{2}\right)}{2\left(4 k(\theta-1)-\lambda^{2}\right)\left(2 k(\theta-1)-\lambda^{2}\right)}>0, p_{2}^{\mathrm{RS} *}- \\
& p_{2}^{\mathrm{C} *}=\frac{\lambda^{2}+2(s+\theta-c)\left(k(\theta-1)-\lambda^{2}\right)}{8 k(\theta-1)-4 \lambda^{2}}>\frac{2 k(\theta-1)-\lambda^{2}}{8 k(\theta-1)-4 \lambda^{2}}=0 . \\
& \text { Then, the Proposition } 1 \text { is proven. } \square
\end{aligned}
$$

\section{Proof of Proposition 2:}

Based on the previous proof, we have the conditions of $s+\theta-1-c>0$ and $k(\theta-1)>$ $\lambda^{2}$. Therefore, $q_{2}^{M S *}-q_{2}^{R S *}=-\frac{k(s+\theta-1-c) \lambda^{2}}{2\left(4 k(\theta-1)-\lambda^{2}\right)\left(2 k(\theta-1)-\lambda^{2}\right)}<0, q_{2}^{C *}-q_{2}^{R S *}=\frac{k(s+\theta-1-c)}{4 k(\theta-1)-2 \lambda^{2}}>0$; $q_{1}^{M S *}-q_{1}^{R S *}=\frac{k(s+\theta-1-c) \lambda^{2}}{2\left(4 k(\theta-1)-\lambda^{2}\right)\left(2 k(\theta-1)-\lambda^{2}\right)}>0, q_{1}^{C *}-q_{1}^{R S *}=\frac{-2 c k+2 k s+\lambda^{2}}{-8 k(\theta-1)+4 \lambda^{2}}=\frac{2 k(c-s)-\lambda^{2}}{8 k(\theta-1)-4 \lambda^{2}}>0$, $\frac{q_{2}^{C *}}{q_{1}^{C *}+q_{2}^{C *}}-\frac{q_{2}^{R S *}}{q_{1}^{R S *}+q_{2}^{R S *}}=0, \frac{q_{2}^{R S *}}{q_{1}^{R S *}+q_{2}^{R S *}}-\frac{q_{2}^{M S *}}{q_{1}^{M S *}+q_{2}^{M S *}}=\frac{2 k(s+\theta-1-c) \lambda^{2}}{8 k^{2}(\theta-1)^{2}-6 k(\theta-1) \lambda^{2}+\lambda^{4}}>0$.

Because of $q_{1}^{C *}-q_{1}^{M S *}=\frac{\left(3 k(\theta-1)-\lambda^{2}\right)^{2}-k^{2}(\theta-1)(9(\theta-1)-8(c-s))}{4\left(4 k(\theta-1)-\lambda^{2}\right)\left(2 k(\theta-1)-\lambda^{2}\right)},(1)$ If $\left(3 k(\theta-1)-\lambda^{2}\right)^{2}>$ $k^{2}(\theta-1)(9(\theta-1)-8(c-s))$, that is $\lambda^{2}<3 k(\theta-1)-k \sqrt{(\theta-1)(9(\theta-1)-8(c-s))}$, then $q_{1}^{C *}-q_{1}^{M S *}>0$; (2) otherwise, $q_{1}^{C *}-q_{1}^{M S *}<0$.

Then, the Proposition 2 is proven.

Similar to the proof of Propositions 1 and 2, we omit the proof of Propositions 3-7.

\section{References}

1. Wu, Z.; Pagell, M. Balancing priorities: Decision-making in sustainable supply chain management. J. Oper. Manag. 2011, 29, 577-590. [CrossRef]

2. Linton, J.D.; Klassen, R.; Jayaraman, V. Sustainable supply chains: An introduction. J. Oper. Manag. 2007, 25, 1075-1082. [CrossRef]

3. Li, G.; Li, L.; Choi, T.M.; Sethi, S.P. Green supply chain management in Chinese firms: Innovative measures and the moderating role of quick response technology. J. Oper. Manag. 2020, 66, 958-988. [CrossRef]

4. Shamdasani, P.; Chon-Lin, G.O.; Richmond, D. Exploring green consumers in an oriental culture: Role of personal and marketing mix factors. NA-Adv. Consum. Res. 1993, 20, 488-493.

5. Agi, M.A.; Yan, X. Greening products in a supply chain under market segmentation and different channel power structures. Int. J. Prod. Econ. 2020, 223, 107523. [CrossRef]

6. Hong, Z.; Wang, H.; Gong, Y. Green product design considering functional-product reference. Int. J. Prod. Econ. 2019, 210, 155-168. [CrossRef]

7. Bian, J.; Zhang, G.; Zhou, G. Manufacturer vs. consumer subsidy with green technology investment and environmental concern. Eur. J. Oper. Res. 2020, 287, 832-843. [CrossRef]

8. Su, J.C.; Wang, L.; Ho, J.C. The impacts of technology evolution on market structure for green products. Math. Comput. Model. 2012, 55, 1381-1400. [CrossRef]

9. Li, X.; Li, Y. On green market segmentation under subsidy regulation. Supply Chain Manag. 2017, 22, 284-294. [CrossRef]

10. Li, X.; Li, Y. Chain-to-chain competition on product sustainability. J. Clean. Prod. 2016, 112, 2058-2065. [CrossRef]

11. Sarkar, B.; Mridha, B.; Pareek, S.; Sarkar, M.; Thangavelu, L. A flexible biofuel and bioenergy production system with transportation disruption under a sustainable supply chain network. J. Clean. Prod. 2021, 317, 128079. [CrossRef]

12. Deng, W.; Feng, L.; Zhao, X.; Lou, Y. Effects of supply chain competition on firms' product sustainability strategy. J. Clean. Prod. 2020, 275, 124061. [CrossRef]

13. Sim, J.; El Ouardighi, F.; Kim, B. Economic and environmental impacts of vertical and horizontal competition and integration. Nav. Res. Logist. 2019, 66, 133-153. [CrossRef]

14. Gao, J.; Xiao, Z.; Wei, H. Competition and coordination in a dual-channel green supply chain with an eco-label policy. Comput. Ind. Eng. 2021, 153, 107057. [CrossRef]

15. Zhang, L.; Wang, J.; You, J. Consumer environmental awareness and channel coordination with two substitutable products. Eur. J. Oper. Res. 2015, 241, 63-73. [CrossRef]

16. Hong, Z.; Wang, H.; Yu, Y. Green product pricing with non-green product reference. Transp. Res. Part E Logist. Transp. Rev. 2018, 115, 1-15. [CrossRef]

17. Zhang, Q.; Zhao, Q.; Zhao, X.; Tang, L. On the introduction of green product to a market with environmentally conscious consumers. Comput. Ind. Eng. 2020, 139, 106190. [CrossRef]

18. Yadav, D.; Kumari, R.; Kumar, N.; Sarkar, B. Reduction of waste and carbon emission through the selection of items with cross-price elasticity of demand to form a sustainable supply chain with preservation technology. J. Clean. Prod. 2021, 297, 126298. [CrossRef]

19. Ghosh, D.; Shah, J. Supply chain analysis under green sensitive consumer demand and cost sharing contract. Int. J. Prod. Econ. 2015, 164, 319-329. [CrossRef]

20. Hong, Z.; Guo, X. Green product supply chain contracts considering environmental responsibilities. Omega 2019, 83, 155-166. [CrossRef] 
21. Dong, C.; Liu, Q.; Shen, B. To be or not to be green? Strategic investment for green product development in a supply chain. Transp. Res. Part E Logist. Transp. Rev. 2019, 131, 193-227. [CrossRef]

22. Li, G.; Wu, H.; Sethi, S.P.; Zhang, X. Contracting green product supply chains considering marketing efforts in the circular economy era. Int. J. Prod. Econ. 2021, 234, 108041. [CrossRef]

23. Zhu, W.; He, Y. Green product design in supply chains under competition. Eur. J. Oper. Res. 2017, 258, 165-180. [CrossRef]

24. Guo, S.; Choi, T.M.; Shen, B. Green product development under competition: A study of the fashion apparel industry. Eur. J. Oper. Res. 2020, 280, 523-538. [CrossRef]

25. Ma, P.; Zhang, C.; Hong, X.; Xu, H. Pricing decisions for substitutable products with green manufacturing in a competitive supply chain. J. Clean. Prod. 2018, 183, 618-640. [CrossRef]

26. Du, P.; Yang, X.; Xu, L.; Tan, Y.; Li, H. Green design strategies of competing manufacturers in a sustainable supply chain. J. Clean. Prod. 2020, 265, 121853. [CrossRef]

27. Shan, H.; Zhang, C.; Wei, G. Bundling or Unbundling? Pricing Strategy for Complementary Products in a Green Supply Chain. Sustainability 2020, 12, 1331. [CrossRef]

28. Cao, Y.; Tao, L.; Wu, K.; Wan, G. Coordinating joint greening efforts in an agri-food supply chain with environmentally sensitive demand. J. Clean. Prod. 2020, 277, 123883. [CrossRef]

29. Guo, X.; Cheng, L.; Liu, J. Green supply chain contracts with eco-labels issued by the sales platform: Profitability and environmental implications. Int. J. Prod. Res. 2020, 58, 1485-1504. [CrossRef]

30. Wang, Z.; Zhang, J.; Zhao, H. The Selection of Green Technology Innovations under Dual-Credit Policy. Sustainability 2020, 12, 6343. [CrossRef]

31. Yang, X.; Xu, M.; Zhang, W. Can Design for the Environment be Worthwhile? Green Design for Manufacturers Brands When Confronted with Competition from Store Brands. Sustainability 2020, 12, 1078. [CrossRef]

32. Cai, Y.; Choi, T.; Feng, L.; Li, Y. Producer's Choice of Design-for-Environment under Environmental Taxation. Eur. J. Oper. Res. 2021, 297, 532-544. [CrossRef]

33. Mu, Z.; Zheng, Y.; Sun, H. Cooperative Green Technology Innovation of an E-Commerce Sales Channel in a Two-Stage Supply Chain. Sustainability 2021, 13, 7499. [CrossRef]

34. Garai, A.; Chowdhury, S.; Sarkar, B.; Roy, T.K. Cost-effective subsidy policy for growers and biofuels-plants in closed-loop supply chain of herbs and herbal medicines: An interactive bi-objective optimization in T-environment. Appl. Soft Comput. 2021, 100, 106949. [CrossRef]

35. Yalabik, B.; Fairchild, R.J. Customer, regulatory, and competitive pressure as drivers of environmental innovation. Int. J. Prod. Econ. 2011, 131, 519-527. [CrossRef]

36. Subramanian, R.; Gupta, S.; Talbot, B. Product design and supply chain coordination under extended producer responsibility. Prod. Oper. Manag. 2009, 18, 259-277. [CrossRef]

37. Shen, B.; Zhu, C.; Li, Q.; Wang, X. Green technology adoption in textiles and apparel supply chains with environmental taxes. Int. J. Prod. Res. 2020, 59, 4157-4174. [CrossRef]

38. Chen, J.Y.; Dimitrov, S.; Pun, H. The impact of government subsidy on supply Chains' sustainability innovation. Omega 2019, 86, 42-58. [CrossRef]

39. Atasu, A.; Subramanian, R. Extended producer responsibility for e-waste: Individual or collective producer responsibility? Prod. Oper. Manag. 2012, 21, 1042-1059. [CrossRef]

40. Yang, H.; Chen, W. Retailer-driven carbon emission abatement with consumer environmental awareness and carbon tax: Revenue-sharing versus cost-sharing. Omega 2018, 78, 179-191. [CrossRef]

41. Carus, M.; Eder, A.; Beckmann, J. GreenPremium prices along the value chain of biobased products. Ind. Biotechnol. 2014, 10, 83-88. [CrossRef]

42. Zhang, C.T.; Wang, H.X.; Ren, M.L. Research on pricing and coordination strategy of green supply chain under hybrid production mode. Comput. Ind. Eng. 2014, 72, 24-31. [CrossRef]

43. Ferrer, G.; Swaminathan, J.M. Managing new and remanufactured products. Manag. Sci. 2006, 52, 15-26. [CrossRef]

44. Yenipazarli, A. Managing new and remanufactured products to mitigate environmental damage under emissions regulation. Eur. J. Oper. Res. 2016, 249, 117-130. [CrossRef]

45. Chen, C. Design for the environment: A quality-based model for green product development. Manag. Sci. 2001, 47, 250-263. [CrossRef]

46. Gao, J.; Xiao, Z.; Wei, H.; Zhou, G. Active or passive? Sustainable manufacturing in the direct-channel green supply chain: A perspective of two types of green product designs. Transp. Res. Part D Transp. Environ. 2018, 65, 332-354. [CrossRef] 